\title{
Bio Phantoms Mimicking the Dielectric and Mechanical Properties of Human Skin Tissue at Low-Frequency Ranges
}

\author{
Dr. Anubha Kalra ${ }^{1}$, Dr. Andrew Lowe ${ }^{1} \&$ Dr. Gautam Anand ${ }^{1}$ \\ ${ }^{1}$ Institute of Biomedical Technologies, Auckland University of Technology, Auckland, NZ \\ Correspondence: Dr. Anubha Kalra, Institute of Biomedical Technologies, Auckland University of Technology, \\ Auckland, NZ
}

Received: April 1, 2020

Accepted: May 11, 2020

Online Published: May 22, 2020

doi:10.5539/mas.v14n7p1

URL: https://doi.org/10.5539/mas.v14n7p1

\begin{abstract}
Tissue phantoms are widely used as substitute materials for real tissue validation of various newly emerging biomedical technologies such as ultrasound (US), computed tomography (CT), and magnetic resonance imaging (MRI). However, there is no specific recipe for fabricating skin-mimicking phantoms which can mimic both the mechanical and dielectric properties of human skin at lower frequency ranges.

The objective of this paper is to present a variety of tissue-mimicking materials for filling this research gap in the lower frequency range from $20 \mathrm{~Hz}$ to $300 \mathrm{kHz}$. The starting point of our experiments is based on the oil-in-gelatin based tissue-mimicking materials (TMMs) that have shown to mimic the dielectric properties of human skin in higher frequency ranges. This paper examines the mechanical and dielectric performance of five major classes of tissue-mimicking materials (1) Oil-in-gelatin, (2) lignin and graphene nanopowder in gelatin, (3) gelatin and distilled water, (4) mixed oil in gelatin and distilled water, and (5) lignin in gelatin and distilled water.

Mechanical and electrical testing was performed using compression testing and parallel plate method respectively. The effect of electrode polarization was considered in the measured data and the intrinsic impedance values were found to be following the Cole-Cole equation. The Young's modulus range of all tissue-mimicking materials was within the range of skin.
\end{abstract}

Keywords: Tissue Mimicking Materials (TMMs), gelatin, graphene nanopowder, lignin, Cole-Cole plot, dielectric constant, Young's modulus (YM)

\section{Introduction}

Tissue-mimicking (TM) phantoms are vivid models of real human tissue that exhibit realistic properties of tissues in certain areas (Porter et al., n.d.). As real human tissue samples are difficult to obtain and store (Bot et al., 2009) (Singh et al., 2016), tissue phantoms are making a significant contribution to the characterization of the new imaging technologies and medical training. Human skin is the heaviest and vastest organ of the human body, which performs critical functions to human health, especially in regulation and protection. The development of the skin phantoms will facilitate the development of biomedical applications and contribute to skin clinical research, particularly for cosmetic, dermatology, and detection of cutaneous pathology (Kalra et al., 2016)(Garrett et al., 2014)(Moll and Dennis, n.d.)(Sugihara et al., 1991) (Meaney et al., 2012).

Although the field of tissue-mimicking phantoms manufacturing is becoming more attractive and many researchers have achieved active explorations in it, there is no specific recipe for fabricating skin-mimicking phantoms that can properly match mechanical and electrical properties of human skin. The dielectric properties of most existing skin-mimicking phantoms were measured at high frequencies (normally over $500 \mathrm{MHz}$ ) to satisfy the requirement of microwave imaging technology (Meaney et al., 2012) (Popovic et al., 2005). To date, less research has been done on phantoms mimicking human skin at low frequencies because of the error introduced due to the electrode-polarization effect.

However, this relatively blank research area has attracted more attention recently with the gradual clinical application of low-frequency technologies such as electrical impedance tomography (EIT) (Riu and Anton, 2010) (Ahn et al., 2010). The adjustable frequency of currently commercial devices of EIT for clinical use is below 150 kHz (Orschulik and Menden, 2017). 
The objective of this paper is to present a variety of tissue-mimicking materials for manufacturing skin phantoms, which can mimic the mechanical and electrical properties of real human tissue under different physical conditions in low-frequency ranges (from $20 \mathrm{~Hz}$ to $300 \mathrm{kHz}$ ). Also, the skin phantoms should present stable, flexible, reliable properties and can be prepared in a standard lab (without expensive machinery) using commonly available chemicals.

Schwan (Schwan, 1994) was the first person to fully described the main features of the dielectric spectrum of most tissues with three dielectric dispersions (Lorenzo et al., 2018), as seen in Figure 1. The changes in dielectric constant occur in three distinct major frequency regions: low-frequency (below $1 \mathrm{kHz})$, radio frequency $(10 \mathrm{kHz}$ to $100 \mathrm{MHz}$ ), and high frequency (over $100 \mathrm{MHz}$ ), and are named $\alpha, \beta$ and $\gamma$ dispersions respectively (Matthie, 2008)(Lorenzo et al., 2018).

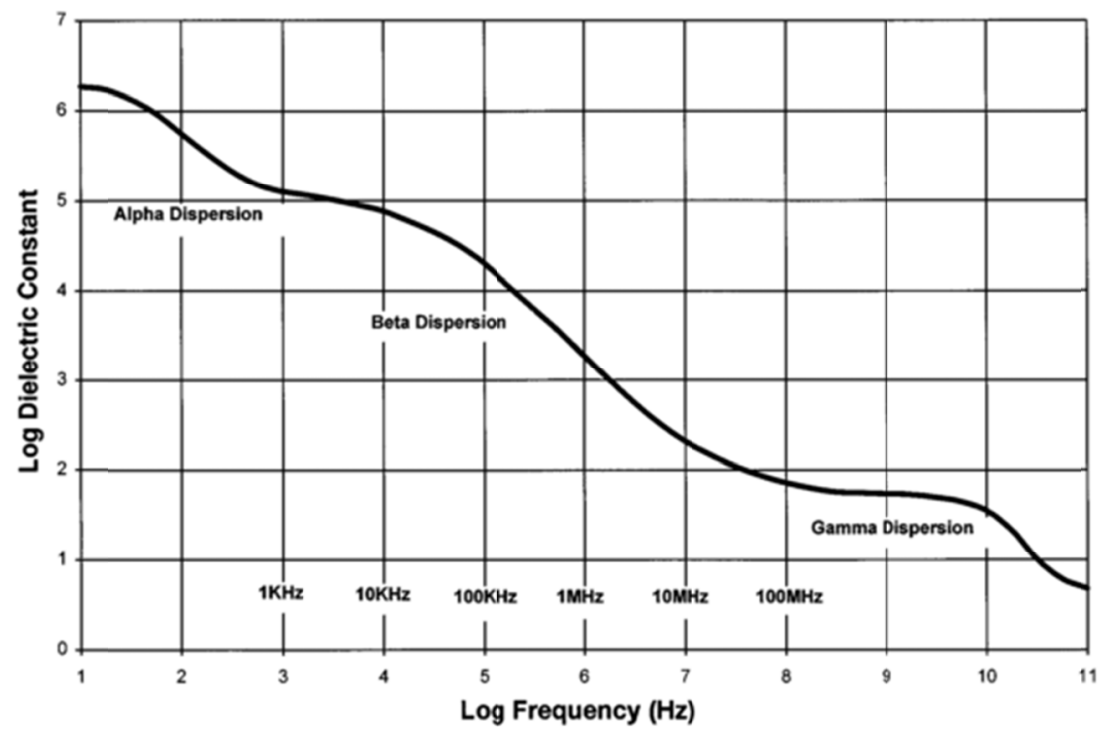

Figure 1. The variation of the relative permittivity $\left(\varepsilon^{\prime}\right)$ with frequency for a typical biological tissue (Lorenzo et al., 2018).

The low-frequency dispersion $\alpha$ is related to ionic diffusion processes at the site of the cellular membrane. The $\gamma$-dispersion of high frequency is due to the polarization of water molecules. However, the range of measurement frequency (from $20 \mathrm{~Hz}$ to $60 \mathrm{kHz}$ ) of our skin phantoms studies belongs to $\alpha$ and $\beta$-dispersions which are commonly considered to be associated with the structure of the cell membranes and their interactions with the intracellular and extra-cellular electrolytes (Pethig R, 1984).

The goal of this study is to prepare skin phantoms that can reflect the dielectric and mechanical properties of real skin. Reliable measurement and prediction data of the dielectric and mechanical properties of actual skin have been summarized in this section which will be used for comparison purposes in this study.

Human skin can be considered as a heterogeneous tissue consisting of four layers: Stratum Corneum, Epidermis, Dermis, and Hypodermis (Kalra et al., 2016)(Groves et al., 2012). The mechanical properties of skin are usually determined by Young's Modulus.

Young's Modulus of skin measured cross-sectionally using indentation tests is between 5 to $100 \mathrm{kPa}$. However, measured values can depend on indenter geometry and whether quasistatic or dynamic testing is being performed. Values of between $25 \mathrm{kPa}$ and $140 \mathrm{MPa}$ are typical for both tensile and torsion tests. Tensile tests indicate higher Young's Modulus at higher strain rates, indicating that skin is viscoelastic. Young's Modulus measured by suction tests spans $25 \mathrm{kPa}$ to $260 \mathrm{kPa}$, which is between the ranges found from indentation (thickness-mode) and tensile/torsion (in-plane mode). Suction tests are a common choice for skin testing, as they are easy to apply in vivo and allow for additional deformation detection through, for example, imaging ultrasound [18].

The study of the dielectric properties of actual tissues belongs to basic and applied sciences. The theoretical aspects and main findings of this topic have been extensively reviewed in (Pethig R, 1984) (Kyle et al., 2004)(Cole and Cole, 1941)(Schwan, 1994)(Cole, 1972). The systematic records of the electrical properties of human tissue began in the 1950s (C. Gabriel et al., 1996). Since that time, a large amount of measurement data 
records about the dielectric properties of biological tissues have been tested and collected. In 1996, Gabriel et al. (C. Gabriel et al., 1996) presented an almost complete summarization of the data available in the literature, which includes the electrical properties of 30 types of tissues in broad frequency ranges from kilo $\mathrm{Hz}$ to $\mathrm{Mega}$ Hz. Amongst them, the collection of skin data is mainly divided into wet skin and dry skin (see table 1). In the same year, Gabriel et al. again experimentally measured the dielectric properties of amount tissues using swept-frequency network and impedance analyzers in the frequency range $10 \mathrm{~Hz}$ to $20 \mathrm{GHz}$.

The measuring data were shown to fall well within the literature data in (C. Gabriel et al., 1996) of the vast body. Later, all the dielectric properties data of the spectrum from $10 \mathrm{~Hz}$ to $100 \mathrm{GHz}$ was modeled by a four-pole Cole-Cole model (S. Gabriel et al., 1996):

$$
\varepsilon(\omega)=\varepsilon_{\infty}+\sum_{n=1}^{4} \Delta \varepsilon_{n} / 1+\left(j \omega \tau_{n}\right)^{1-\alpha_{n}}+\sigma_{i} / j \omega \varepsilon_{0}
$$

Where $\sigma_{i}$ is the ionic conductivity of the tissue at very low frequency, $\varepsilon_{\infty}$ is the relative permittivity in the infinite frequency, $\tau$ is relaxation time and $\omega$ is the angular frequency, $\Delta \varepsilon_{n}$ is the magnitude of the dispersion and $\alpha$ is a parameter that depends on materials' properties.

Table 1. Parameters used to estimate dielectric properties of dry and wet skin

\begin{tabular}{ccccccccccccccc}
\hline $\begin{array}{c}\text { Tissue } \\
\text { type }\end{array}$ & $\varepsilon_{\infty}$ & $\Delta \varepsilon_{1}$ & $\begin{array}{c}\tau_{1} \\
(\mathbf{p s})\end{array}$ & $\alpha_{1}$ & $\Delta \varepsilon_{2}$ & $\begin{array}{c}\tau_{2} \\
(\mathbf{n s})\end{array}$ & $\alpha_{2}$ & $\Delta \varepsilon_{3}$ & $\begin{array}{c}\tau_{3} \\
(\mu s)\end{array}$ & $\alpha_{3}$ & $\Delta \varepsilon_{4}$ & $\begin{array}{c}\tau_{4} \\
(\boldsymbol{m s})\end{array}$ & $\alpha_{4}$ & $\sigma$ \\
\hline $\begin{array}{c}\text { Dry } \\
\text { skin }\end{array}$ & 4.0 & 32.0 & 7.23 & 0.00 & 1100 & 32.48 & 0.2 & 0 & $N$ & $N$ & 0 & $N$ & $N$ & $2 \mathrm{e}-4$ \\
$\begin{array}{l}\text { Wet } \\
\text { skin }\end{array}$ & 4.0 & 39.0 & 7.96 & 0.10 & 280 & 79.58 & 0 & $3 \mathrm{e} 4$ & 1.59 & 0.16 & $3 \mathrm{e} 4$ & 1.592 & 0.2 & $4 \mathrm{e}-4$ \\
\hline
\end{tabular}

Parameters of equation (1) are used to predict the dielectric properties of skin tissue in figures 2 and 3.

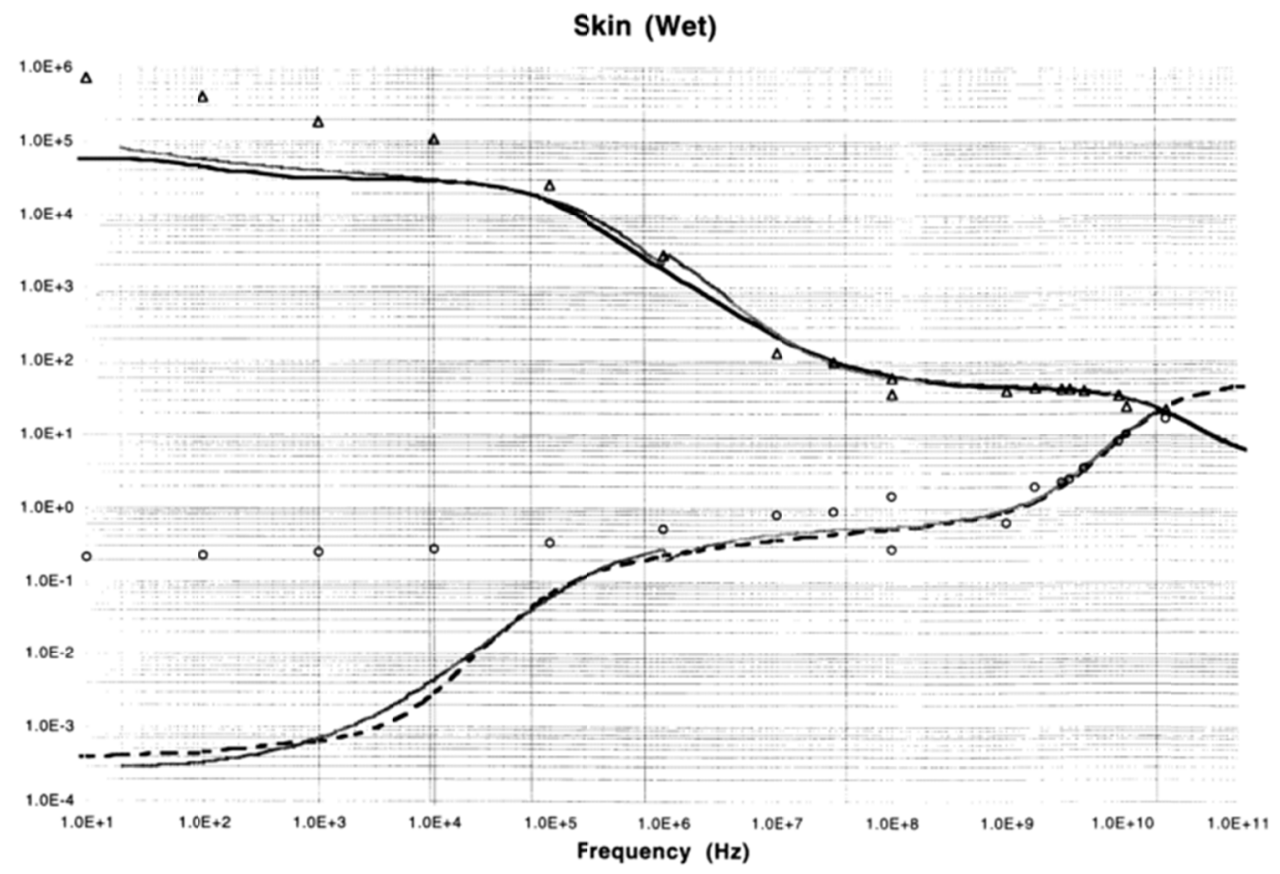

Figure 2. The relative permittivity properties (upper line) and the conductivity (lower line) of wet skin (S. Gabriel et al., 1996). 


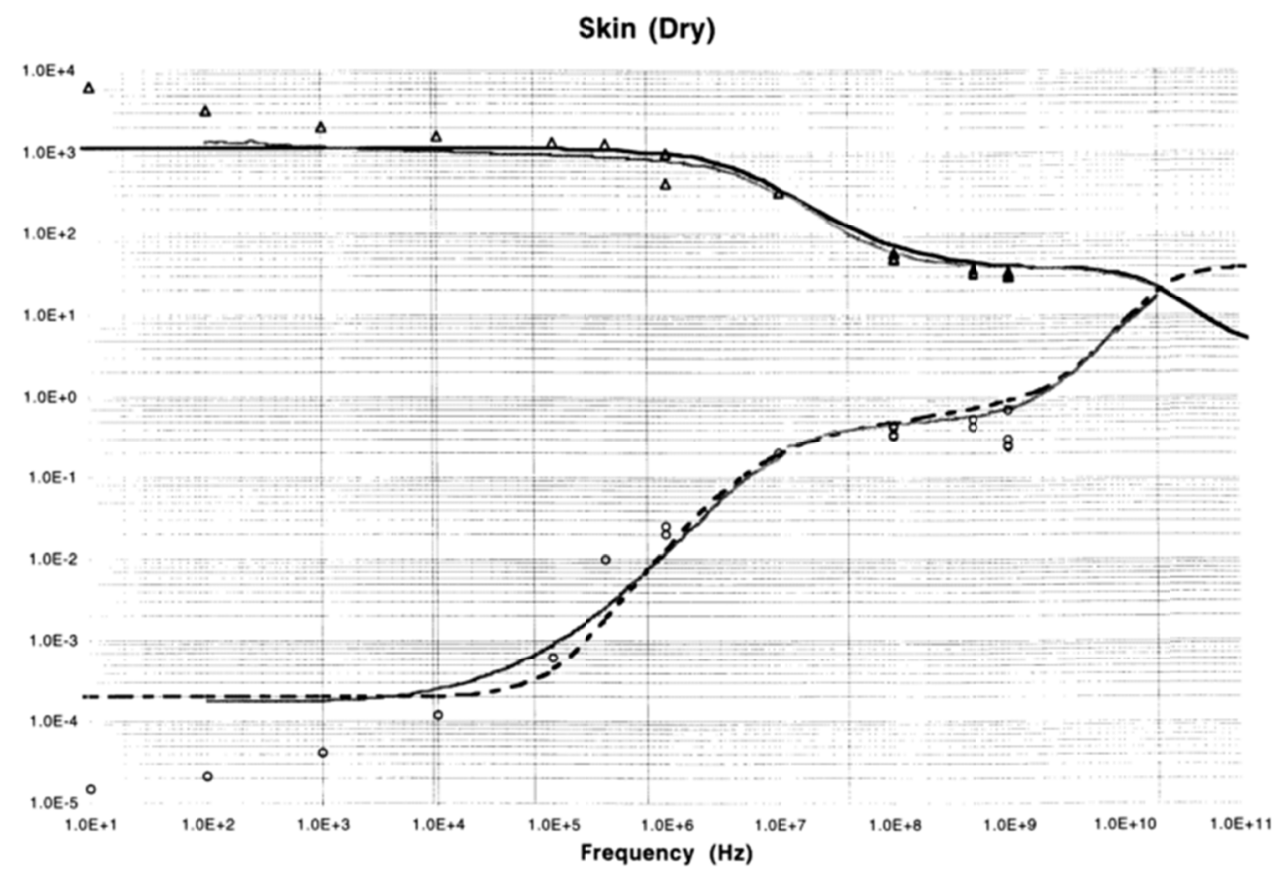

Figure 3. The relative permittivity properties (upper line) and the conductivity (lower line) of dry skin (S. Gabriel et al., 1996).

In the last decades, several skin tissue phantoms have been presented using different tissue-mimicking materials (TMMs). Depending on their main composition, there are mainly three types of TMMs- water-based, oil-in-gelatin, and carbon-rubber-based(Garrett et al., 2014), (Moll and Dennis, n.d.). Water-based phantoms are easily evaporated by air exposure and are not mechanically robust [6], (Abrelli et al., 2017), (Manuscript, 2011). Therefore, they are not considered suitable for this study.

No direct references have been found to prepare TMMs which are tested in low-frequency ranges, thus the existing techniques to prepare TMMs suitable for higher frequency testing will be used as a starting point in this study.

For oil-in-gelatin materials, the content of gelatin and the content of mineral oil are two parameters that mainly regulate the properties of the phantoms, and both can change the electrical properties individually. The carbon-rubber-based TMMs are made from mixtures of carbon as conductive filler and rubber as the insulating matrix. Garrett in 2004 (Garrett et al., 2014) tested several types of TMMs using carbon black and graphite as carbon filler, silicon, and urethane rubber as rubber matrix through varying the concentrations of carbon filler to test their dielectric properties in $1 \sim 10 \mathrm{GHz}$ frequency range.

The methods and materials adopted to prepare TMMs for low-frequency range testing are mentioned in section II.

\section{Methods and Materials}

As an exploratory study, the direction of exploration in each subsequent phase is always based on the experimental performance of the previous phase. Figure 4 shows the general process of the methodology adopted in this research. 


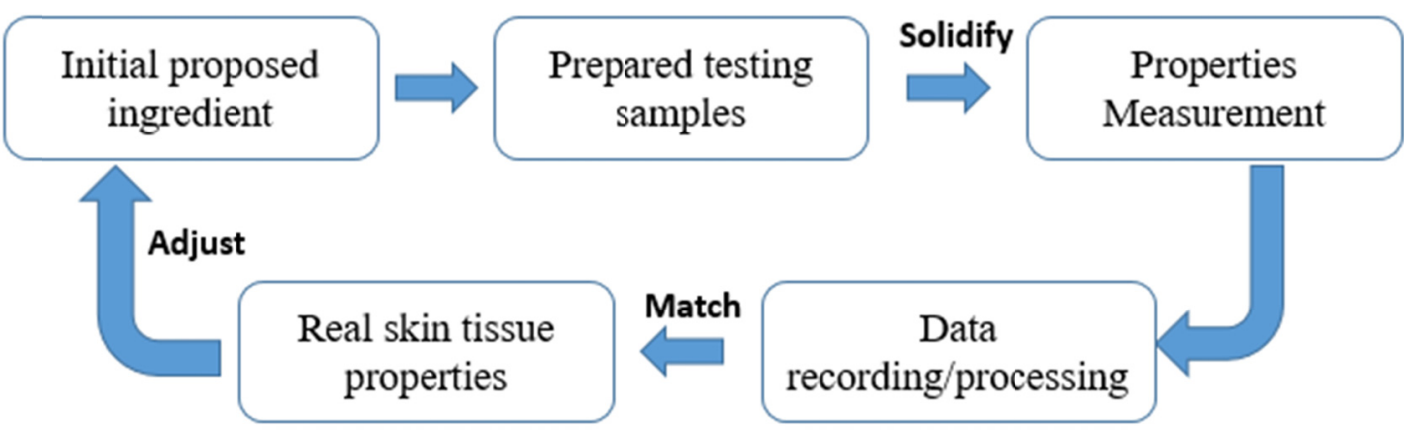

Figure 4. The main steps of this research

The specific content of our experiment can be summarized in three stages. A similar recipe of the oil-in-gelatin TMMs in (Lazebnik et al., 2005)(Madsen et al., 1982) will be applied, and then lignin, carbon-based materials (graphene Nanopowder) will be added.

The flow chart Figure 5 below shows the direction of this experiment. A list of chemicals used to prepare skin phantoms is presented in table 2 .

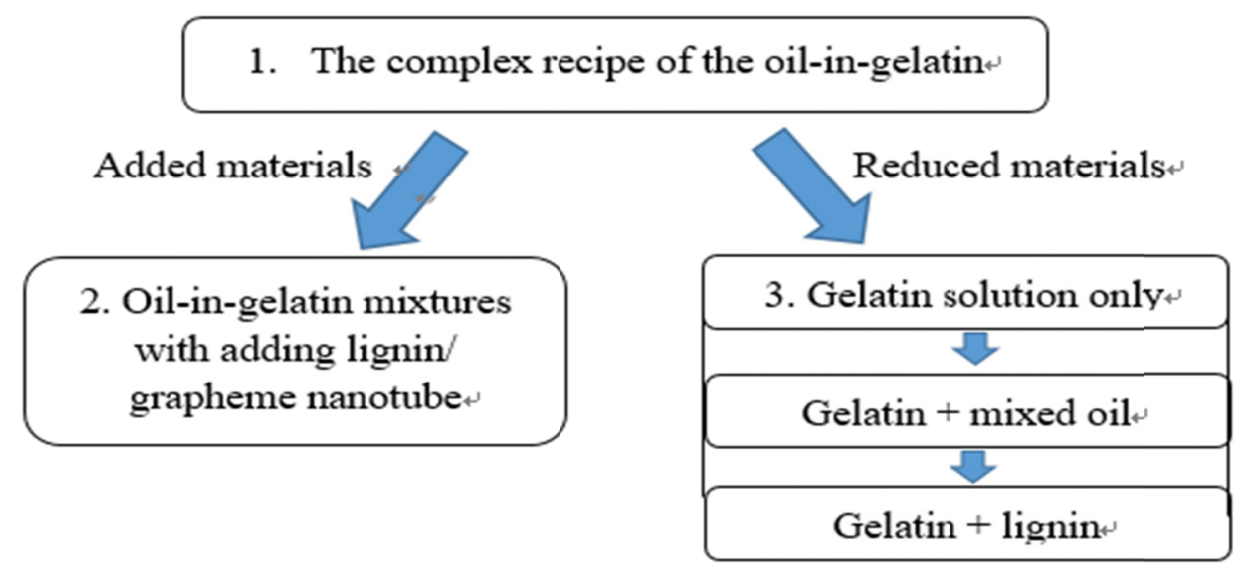

Figure 5. The direction and the recipes of this research

Table 2. Details of the chemicals used in skin phantom preparation

\begin{tabular}{cccc}
\hline & Product's name & Description & Company's details \\
\hline Matrix & Gelatin LR & Lgela8iE-25108-500g & ECP ltd \\
material & & & \\
& Isopropyl Alcohol & $99.97 \%$ pure & Pure Nature \\
& P-Toluic acid 98\% & CAS 99-94-5 & Sigma-Aldrich \\
Additive & Safflower oil & CAS $8001-23-8$ & Pure Nature \\
s & Kerosene oil & UN 1223 & TMK Packers LTD \\
& Liquid surfactant & Original 750 mL & Palmolive \\
& & & (Australia) \\
& Lignin & CAS $8068-05-01$ & Sigma-Aldrich \\
& Graphene Nano power & A0-4: $60 \mathrm{~nm}$ & Graphene \\
& & & Supermarket \\
\hline
\end{tabular}




\subsection{Oil-in-Gelatin TMM}

The investigated materials are mainly a mixture of gelatin solution and a solution of mixed oil (50 vol\% kerosene and $50 \mathrm{vol} \%$ safflower oil). The volume content of the mixed oil (from 0 to $40 \%$ ) is the variation factor to tune the properties of the prepared samples (details in table 3).

For comparison purposes, samples without adding oil were also prepared. The five main steps of preparing the oil-in-gelatin TMMs are described below.

Step 1: Prepare isopropyl alcohol-based solvent by mixing p-toluic acid (powder) with n-propanol.

Step 2: Add the solvent produced in Step I using a quantitative pipette into a new small beaker. Add the desired amount of deionized (DI) water and mix the solution at room temperature until the solution becomes white.

Step 3: Add dry mass gelatin into the solution and keep stirring. Heat and stir the mixture on a hotplate at $100^{\circ} \mathrm{C}$ of temperature until the mixture becomes transparent (see figure 6).
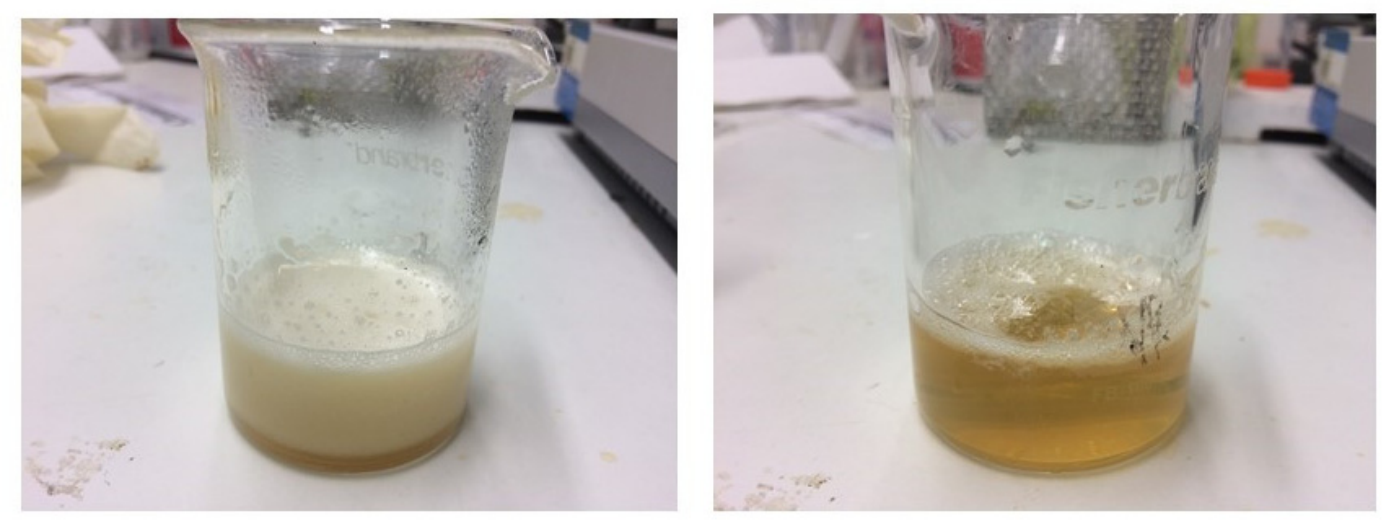

Figure 6. The gelatin solution changed from turbid (left) to transparent (right)

Step 4: Prepare the desired amount of mixed oil (50 vol\% kerosene and 50 vol\% safflower oil) in another beaker and heat at $50{ }^{\circ} \mathrm{C}$. Pour the gelatin mixture prepared in step 3 and liquid surfactant into the beaker.

Step 5: Stop stirring when the emulsion becomes uniform and almost white (about 2 minutes). Remove all air bubbles and pour the solution into a mold. (Figure 7). 

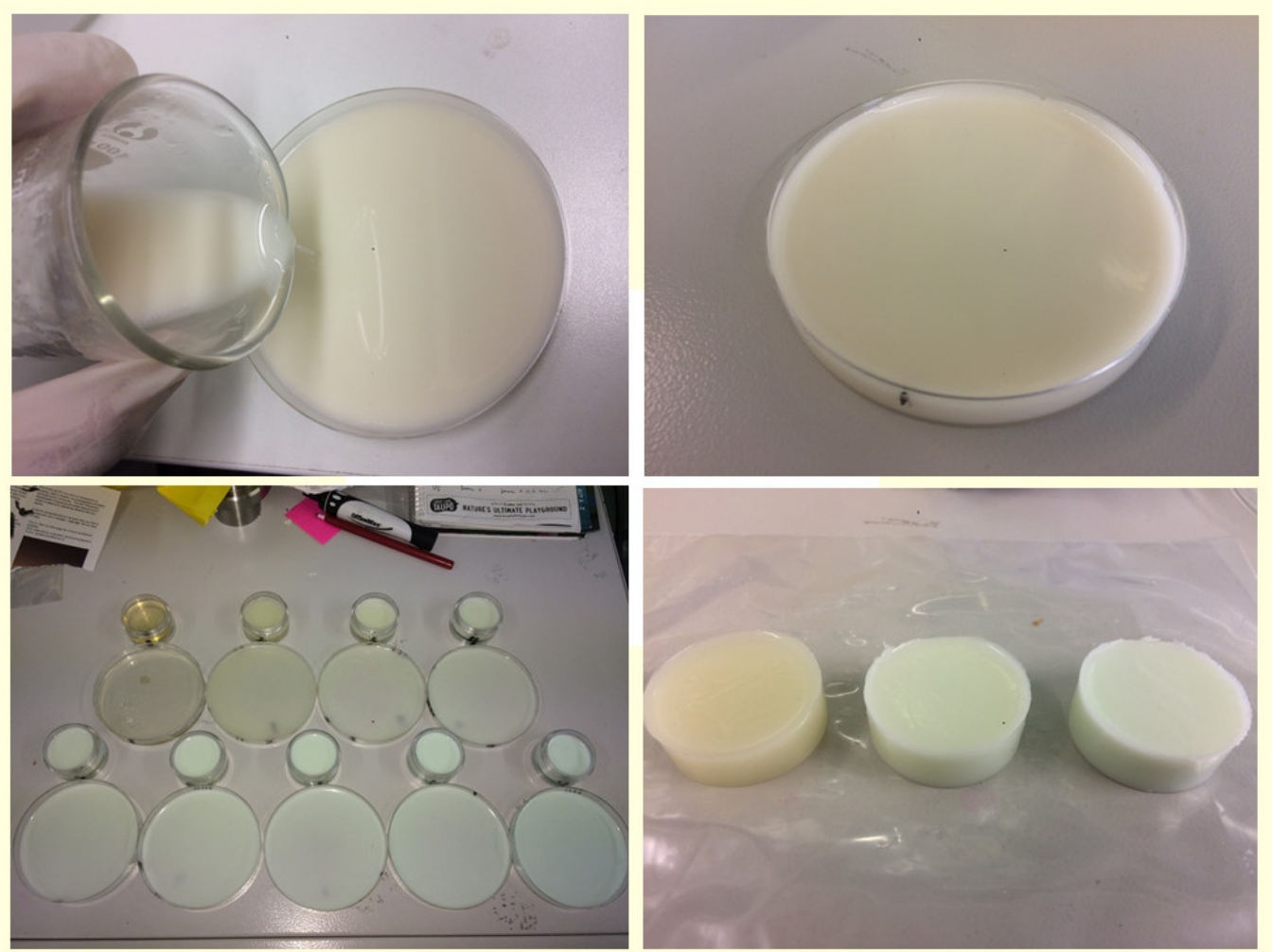

Figure 7. The oil-in-gelatin TMMs

Table 3. The concentration of each ingredient in oil-in-gelatin TMMs samples

\begin{tabular}{cccccccc}
\hline \multirow{2}{*}{ o. } & \multicolumn{2}{c}{ mixed oil } & p-toluic acid & Isopropyl Alcohol & DI water & Gelatin & surfactant \\
\cline { 2 - 8 } & vol\% & $w t \%$ & $w t \%$ & $w t \%$ & $w t \%$ & $w t \%$ & $w t \%$ \\
\hline $\mathbf{1}$ & 0 & 0 & 0.086 & 3.32 & 81.93 & 14.66 & 0 \\
$\mathbf{2}$ & 5 & 4.24 & 0.080 & 3.09 & 78.93 & 13.63 & 2.77 \\
$\mathbf{3}$ & 10 & 8.31 & 0.074 & 2.86 & 70.71 & 12.65 & 5.4 \\
$\mathbf{4}$ & 15 & 12.2 & 0.069 & 2.65 & 65.42 & 11.70 & 7.96 \\
$\mathbf{5}$ & 20 & 16 & 0.063 & 2.44 & 60.30 & 10.80 & 10.41 \\
$\mathbf{6}$ & 25 & 19.6 & 0.058 & 2.25 & 55.43 & 9.92 & 12.74 \\
$\mathbf{7}$ & 30 & 23 & 0.053 & 2.06 & 50.81 & 9.08 & 15 \\
$\mathbf{8}$ & 40 & 29.6 & 0.044 & 1.70 & 41.87 & 7.50 & 19.29 \\
\hline
\end{tabular}

\subsection{Lignin/ Graphene Nanopowder TMM}

Desired quantities of Lignin (0- $6 \mathrm{wt} \%)$ and graphene nanopowder $(0$ to $0.15 \%)$ were added to the gelatin mixture prepared above in Step III (see figure 8). The rest of the recipe was the same as used to prepare oil-in-gelatin mixtures. The concentrations of each ingredient can be seen in tables 4 and 5 .

Table 4. Compositions of oil-in-gelatin samples on adding lignin

\begin{tabular}{ccccccc}
\hline Lignin & mixed oil & p-tol. acid & Isopropyl Alcohol & DI water & Gelatin & surfactant \\
\hline $\mathbf{w t} \%$ & $\mathrm{wt} \%$ & $\mathrm{wt} \%$ & $\mathrm{wt} \%$ & $\mathrm{wt} \%$ & $\mathrm{wt} \%$ & $\mathrm{wt} \%$ \\
$\mathbf{0}$ & 16 & 0.063 & 2.44 & 60.30 & 10.80 & 10.41 \\
$\mathbf{2}$ & 15.65 & 0.062 & 2.40 & 59.10 & 10.59 & 10.20 \\
$\mathbf{4}$ & 15.33 & 0.061 & 2.35 & 57.90 & 10.36 & 10.0 \\
$\mathbf{6}$ & 15.01 & 0.060 & 2.30 & 56.71 & 10.14 & 9.78 \\
\hline
\end{tabular}


Table 5. Compositions of oil-in-gelatin samples on adding graphene Nanopowder

\begin{tabular}{cccccccc}
\hline $\begin{array}{c}\text { Graphene } \\
\text { Nanopowder }\end{array}$ & $\begin{array}{c}\text { Mixed } \\
\text { oil }\end{array}$ & $\begin{array}{c}\boldsymbol{p} \text {-tol. } \\
\text { acid }\end{array}$ & $\begin{array}{c}\text { Isopropyl } \\
\text { Alcohol }\end{array}$ & DI water & Gelatin & Lignin & surfactant \\
\hline $\mathbf{w t} \%$ & $\mathrm{wt} \%$ & $\mathrm{wt} \%$ & $\mathrm{wt} \%$ & $\mathrm{wt} \%$ & $\mathrm{wt} \%$ & $\mathrm{wt} \%$ & $\mathrm{wt} \%$ \\
$\mathbf{0 . 0 0}$ & 15.330 & 0.0610 & 2.350 & 57.90 & 10.360 & 4.00 & 10.0 \\
$\mathbf{0 . 0 5}$ & 15.327 & 0.0608 & 2.345 & 57.89 & 10.355 & 3.998 & 9.983 \\
$\mathbf{0 . 1 0}$ & 15.320 & 0.0608 & 2.344 & 57.30 & 10.350 & 3.996 & 9.982 \\
$\mathbf{0 . 1 5}$ & 15.313 & 0.0608 & 2.342 & 57.80 & 10.34 & 3.994 & 9.977 \\
\hline
\end{tabular}
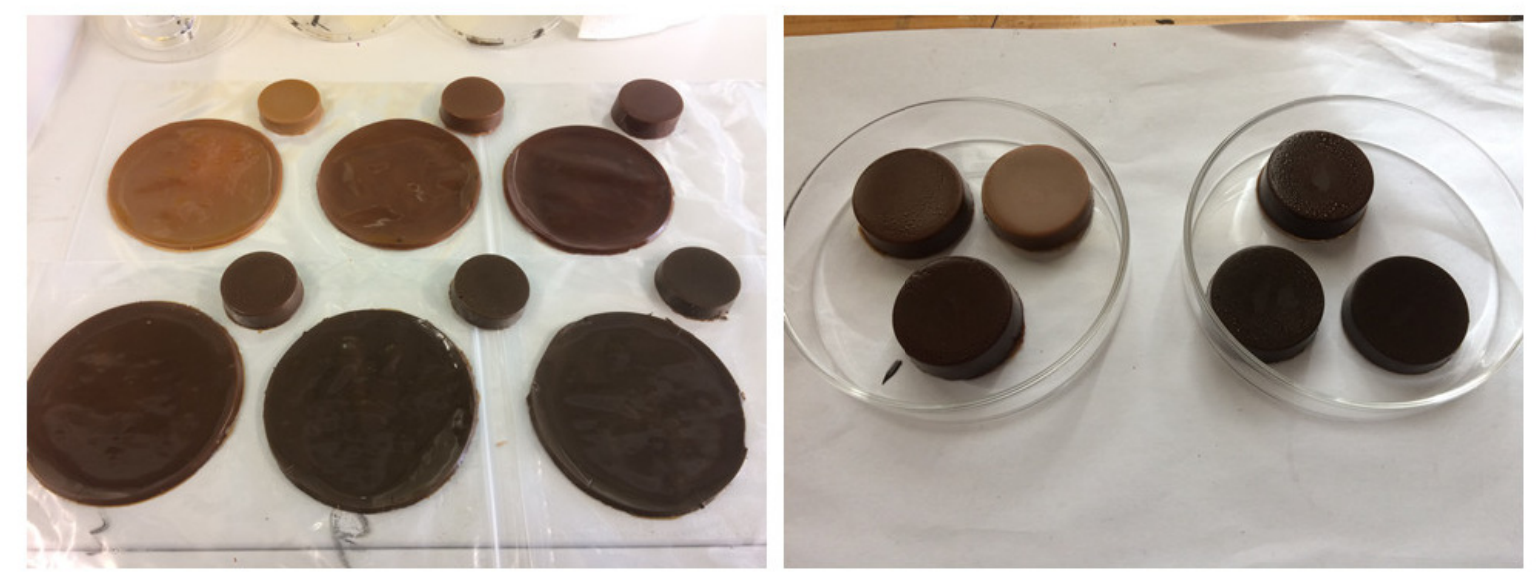

Figure 8. The oil-in-gelatin mixtures on adding lignin/ graphene Nanopowder

\subsection{Gelatin-DI TMM}

Gelatin-DI TMM is prepared by mixing gelatin with DI water, followed by curing at $100^{\circ} \mathrm{C}$ temperature (see figure 9). Different concentrations of Gelatin and DI water were added as seen in table 6.
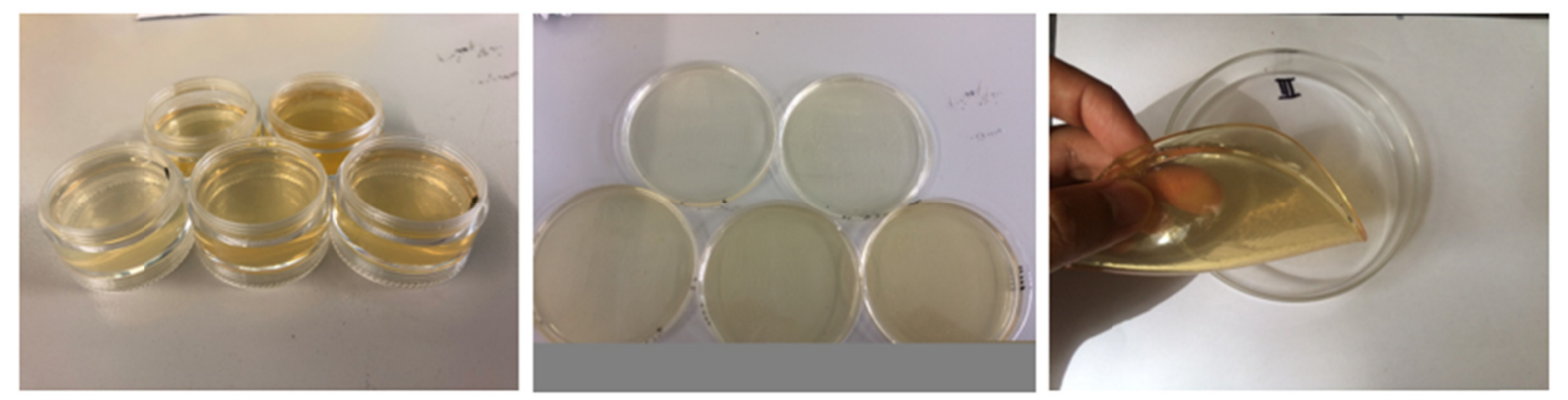

Figure 9. Gelatin-DI TMMs 
Table 6. Concentrations of ingredients in Gelatin-DI TMMs

\begin{tabular}{cccc}
\hline \multirow{2}{*}{ No. } & \multicolumn{2}{c}{ Gelatin } & $\begin{array}{c}\text { DI water } \\
\text { Volume (m) }\end{array}$ \\
\cline { 2 - 3 } & Weight percent (wt \%) & Mass & \\
\hline $\mathbf{1}$ & 10 & 1.67 & 15 \\
$\mathbf{2}$ & 15 & 2.65 & 15 \\
$\mathbf{3}$ & 20 & 3.75 & 15 \\
$\mathbf{4}$ & 25 & 5.00 & 15 \\
$\mathbf{5}$ & 30 & 6.43 & 15 \\
\hline
\end{tabular}

\subsection{Gelatin-DI and Mixed Oil TMM}

Desired quantities of mixed oil (kerosene and sunflower oil) were added to the Gelatin-DI mixtures, and the solution was stirred vigorously before curing to ensure consistency (see figure 10).

The oil increased the viscosity of the solution, and therefore the mixture was stirred for a longer period when the oil percentage was increased.
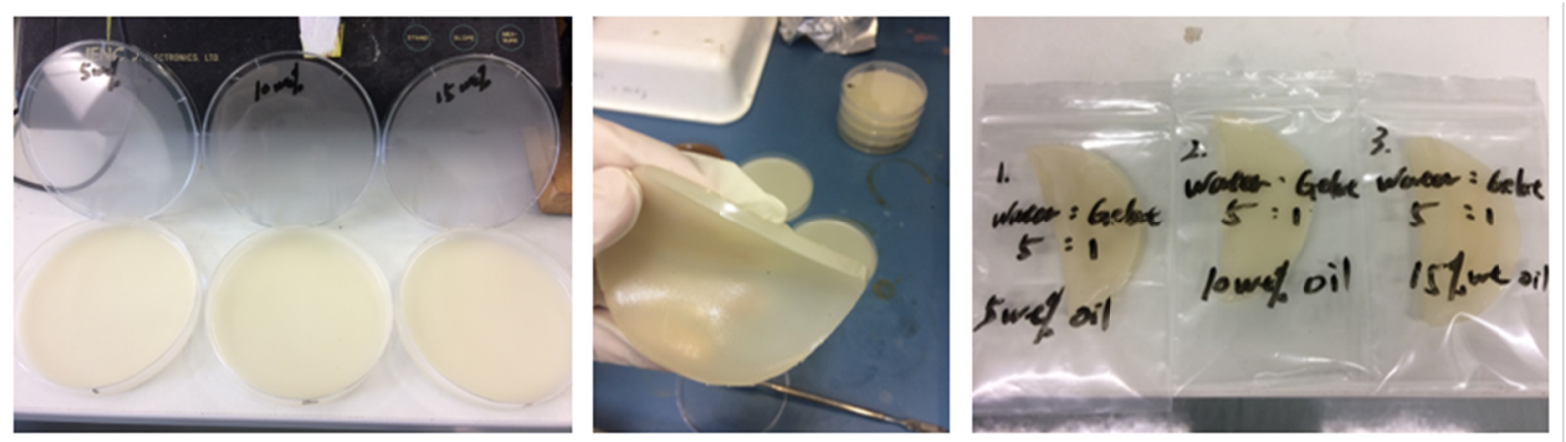

Figure 10. The samples of gelatin solution + mixed oil materials

Table 7. Compositions of gelatin + mixed oil samples

\begin{tabular}{llllll}
\hline No. & $\begin{array}{l}\text { Mixed oil } \\
(\text { wt \%) }\end{array}$ & $\begin{array}{l}\text { Gelatin } \\
(\mathbf{g})\end{array}$ & $\begin{array}{l}\text { DI water } \\
(\boldsymbol{m l})\end{array}$ & $\begin{array}{l}\text { Mixed oil } \\
(\mathbf{g})\end{array}$ \\
\cline { 3 - 5 } & & Designed & Actual & & \\
\hline $\mathbf{1}$ & $5 \mathrm{wt} \%$ & $3 \mathrm{~g}$ & 3.07 & $15 \mathrm{ml}$ & 0.95 \\
$\mathbf{2}$ & $10 \mathrm{wt} \%$ & $3 \mathrm{~g}$ & 3.05 & $15 \mathrm{ml}$ & 2.00 \\
$\mathbf{3}$ & $15 \mathrm{wt} \%$ & $3 \mathrm{~g}$ & 3.05 & $15 \mathrm{ml}$ & 3.18 \\
\hline
\end{tabular}

\subsection{Gelatin-DI and Lignin TMM}

Like mixed oil, lignin increased the viscosity of the solution. Therefore, gelatin and DI solution were mixed with lignin for a longer period. Lignin gave black color to the phantoms (see figure 11). 

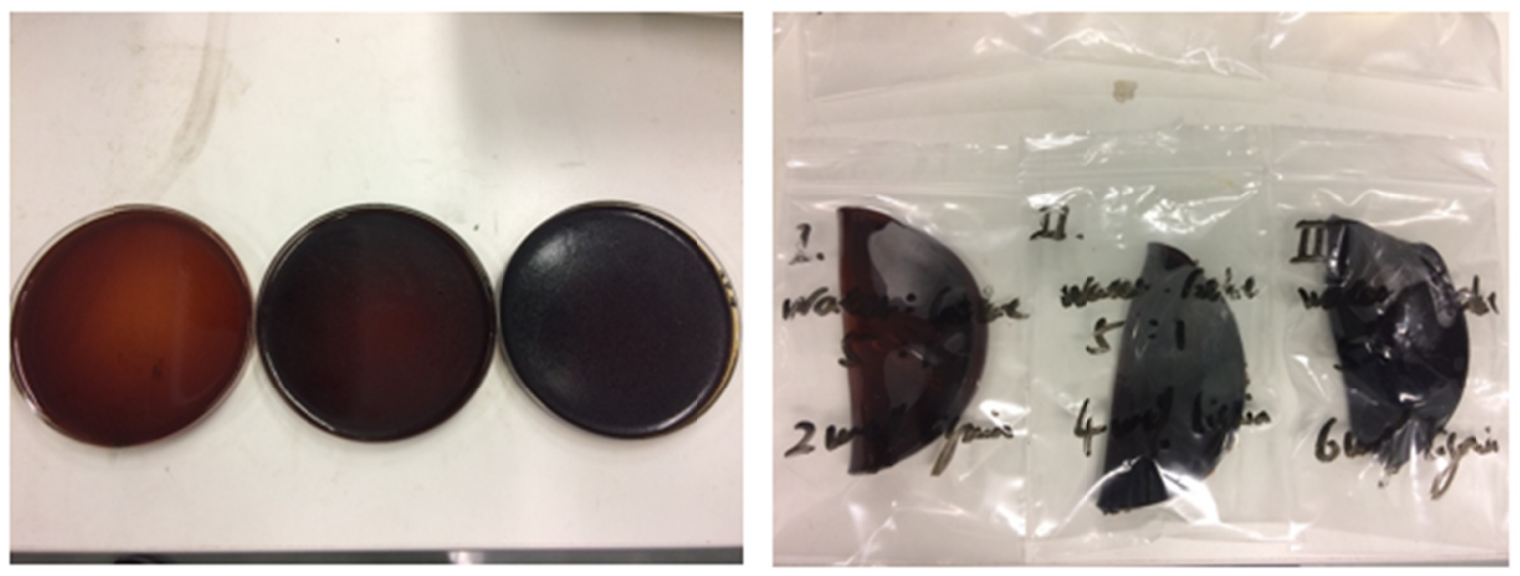

Figure 11. The samples of gelatin solution + lignin

Table 8. Compositions of gelatin + lignin samples

\begin{tabular}{llllll}
\hline No. & $\begin{array}{l}\text { Lignin } \\
(\boldsymbol{w t} \%)\end{array}$ & $\begin{array}{l}\text { Gelatin } \\
(\boldsymbol{g})\end{array}$ & $\begin{array}{l}\text { DI water } \\
(\boldsymbol{m l})\end{array}$ & $\begin{array}{l}\text { Lignin } \\
(\boldsymbol{g})\end{array}$ \\
\cline { 3 - 5 } & & Designed & Actual & & \\
\hline $\mathbf{1}$ & $2 \mathrm{wt} \%$ & $3 \mathrm{~g}$ & 3.02 & $15 \mathrm{ml}$ & 0.37 \\
$\mathbf{2}$ & $4 \mathrm{wt} \%$ & $3 \mathrm{~g}$ & 3.00 & $15 \mathrm{ml}$ & 0.75 \\
$\mathbf{3}$ & $6 \mathrm{wt} \%$ & $3 \mathrm{~g}$ & 3.05 & $15 \mathrm{ml}$ & 1.15 \\
\hline
\end{tabular}

\subsection{Shaping and Sizing of TMM}

The dimensions of materials under testing (MUT) will affect the accuracy of a measurement response. Appropriate and uniform size of MUT will increase the reliability for the final comparison of the experimental data.

The samples were cut into two shapes- cylindrical and circular flat sheets, to measure the mechanical and dielectric properties, respectively.

Cylindrical containers with $36 \mathrm{~mm}$ in inner diameter and $20 \mathrm{~mm}$ in depth were used to solidify cylinder samples as seen in figure 12 .

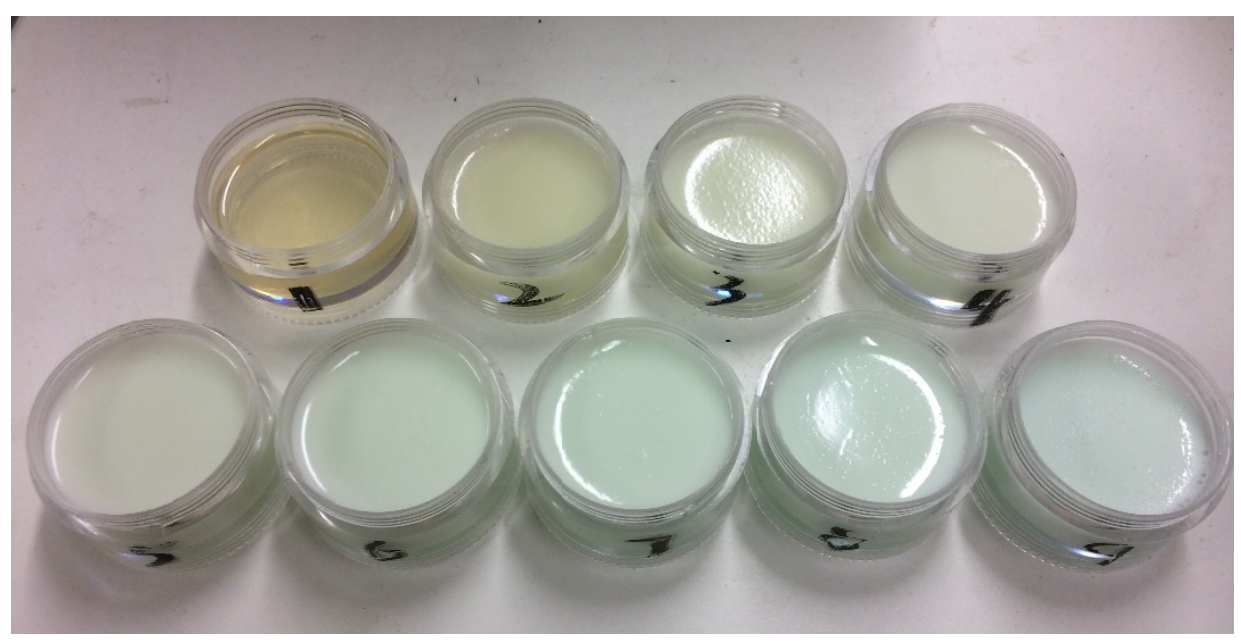

Figure 12. Cylindrical molds to prepare samples for mechanical testing 
A circular cutter consisting of two concentric blades with diameters $44.6 \mathrm{~mm}$ and $52.6 \mathrm{~mm}$ was designed and manufactured. Homogeneous film samples of the TMMs were generated by pouring the molten mixture (above $45^{\circ} \mathrm{C}$ ) into a petri dish with a height of $5 \mathrm{~mm}$ to solidify. After the mixture was cured, the cutting tool was used to cut a circular film of desired dimensions (Figure 13).
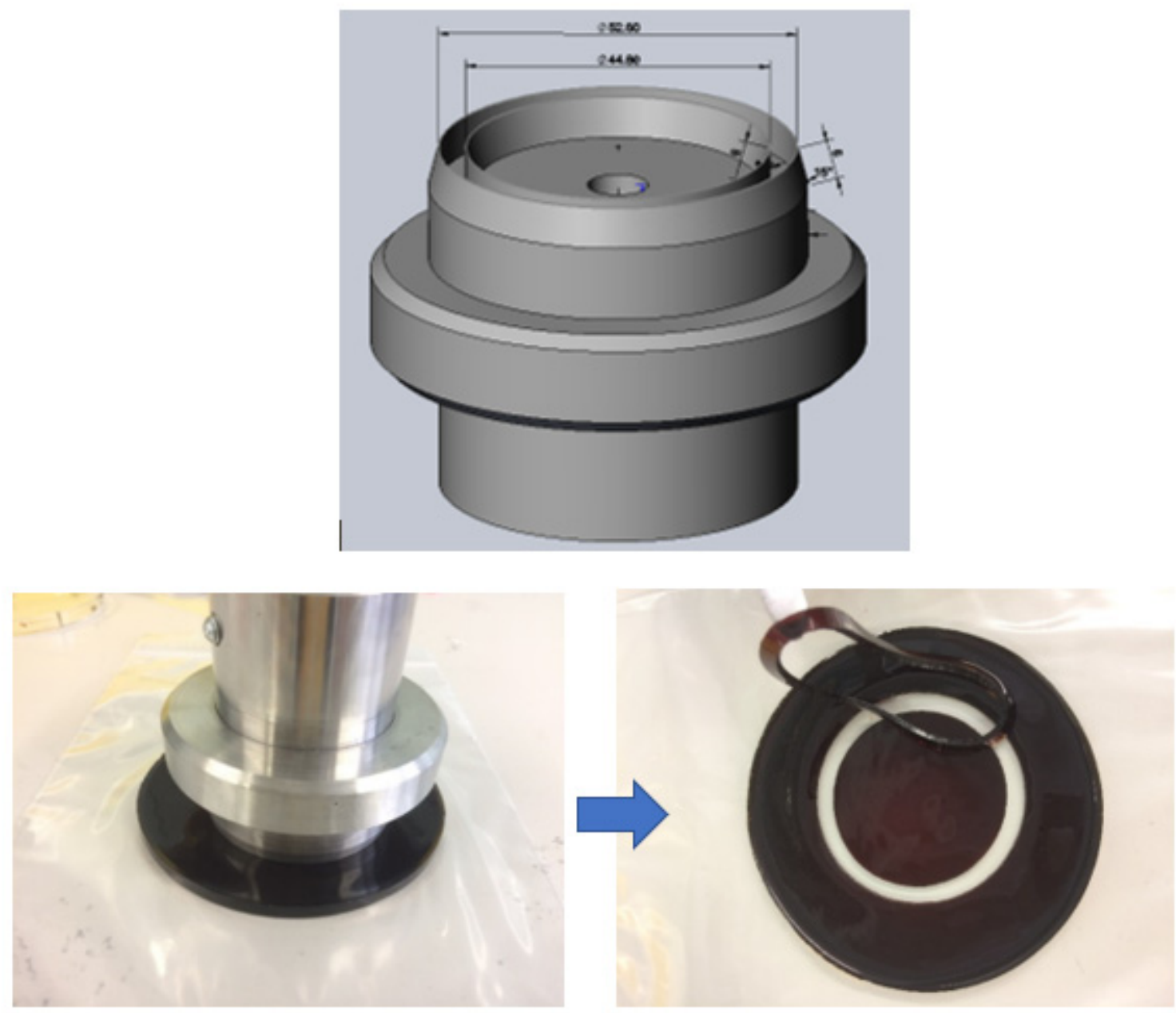

Figure 13. 3D design of a cutting tool and a sample cut in the desired shape

\subsection{Mechanical Testing of the TMMs}

A compression test was performed on the samples to evaluate their Young's Modulus (YM) using a TA.XT.Plus Texture Analyzer from Stable Micro Systems (Surrey, UK). The settings listed in table 9 were used to obtain a stress-strain curve, from which YM was calculated.

Table 9. Settings used in TA.XT.Plus texture analyzer

\begin{tabular}{cc}
\hline Caption & Value \\
\hline Test Mode & Compression \\
Pre-test Speed & $1.00 \mathrm{~mm} / \mathrm{sec}$ \\
Test Speed & $0.5 \mathrm{~mm} / \mathrm{sec}$ \\
Post-Test Speed & $1.00 \mathrm{~mm} / \mathrm{sec}$ \\
Target Mode & Strain \\
Strain & $25 \%$ \\
Trigger type & Force \\
Trigger force & $0.05 \mathrm{~N}$ \\
\hline
\end{tabular}




\subsection{Electrical Testing of TMMs}

There are five kinds of dielectric measurement techniques: Coaxial Probe technique, Transmission Line method, Free Space method, Resonant Cavity method, and Parallel Plate method. A summary of each of them is shown in table 10 .

Table 10. Summary of dielectric measurement techniques (Kalra et al., 2016)

\begin{tabular}{|c|c|c|}
\hline Techniques & Schematic diagram & Features \\
\hline Coaxial Probe & & $\begin{array}{l}\text { Broadband, non-destructive, } \\
\text { convenient; Best for loss MUTs, } \\
\text { liquids or semi-solids }\end{array}$ \\
\hline Transmission Line & & $\begin{array}{l}\text { Broadband; } \\
\text { Best for lossy to loss MUTs; } \\
\text { machineable solids }\end{array}$ \\
\hline Free Space & & $\begin{array}{c}\text { Non-contacting; } \\
\text { Best for high temperatures, lager, } \\
\text { flat samples }\end{array}$ \\
\hline Resonant Cavity & & $\begin{array}{l}\text { Accurate; } \\
\text { Best for low loss MUTs; small } \\
\text { samples, substrates, thin films. }\end{array}$ \\
\hline Parallel Plate & & $\begin{array}{c}\text { Best for low frequencies; thin, flat } \\
\text { sheets. }\end{array}$ \\
\hline
\end{tabular}

This study aims to prepare TMM in a low-frequency range, thus, the parallel plate capacitor method was employed. This method employs a parallel plate conductor to sandwiching the materials under testing between them (Kalra et al., 2016).

A precision LCR meter (E4980A Keysight Technologies, California, USA) was used to measure the electrical properties of TMMs. The operating range of LCR meter is between $20 \mathrm{~Hz}$ and $2 \mathrm{MHz}$, which is suitable for this study. Besides, Keysight 16089B Kelvin Clip Leads connected to two copper circular electrodes $(42.8 \mathrm{~mm}$ in diameter) were also used. The setup of the testing equipment is shown in Figure 14. 


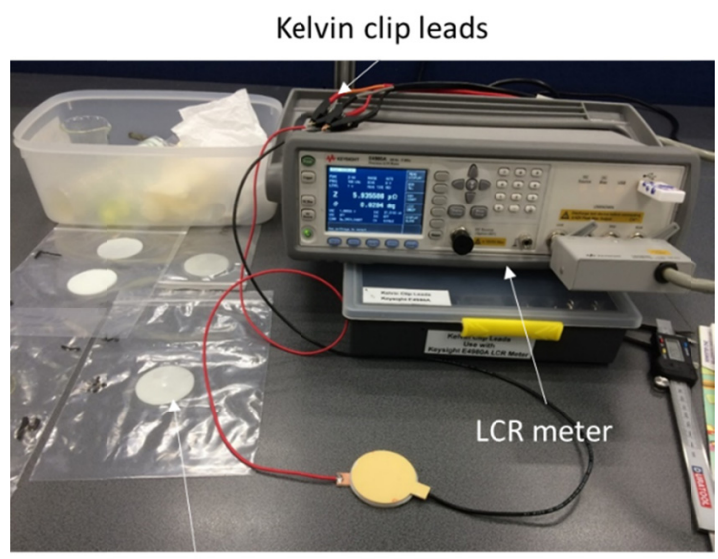

Circular flat films

Figure 14. An LCR Meter and Kelvin clip leads to measure the dielectric constant of circular flat films

The dielectric constant $\left(\varepsilon_{r}\right)$ of the samples was calculated by measuring their impedances $(Z)$ and phase angles $(\varphi)$ across a range of frequencies- $20 \mathrm{~Hz}$ to $300 \mathrm{KHz}$ with 50 frequency points. The equations used to measure the dielectric constant are mentioned below.

$$
\begin{aligned}
& \mathrm{Z}=\mathrm{R}+\mathrm{j} X_{c} \\
& \varphi=\tan ^{-1}\left(\frac{X_{c}}{R}\right) \\
& X_{c}=1 / 2 \pi f_{(H z)} C_{(F)} \\
& \varepsilon_{r}=d \cdot C / \varepsilon_{0} \cdot A
\end{aligned}
$$

where $\mathrm{R}, X_{c}, f, C, \varepsilon_{0}, A$ are resistance, reactance, frequency, capacitance, the permittivity of air, and cross-sectional area of the electrode in SI units respectively.

The measurements were carried out at room temperature, where the circular flat samples were gently pressed between the electrodes, ensuring that the two electrodes are parallel to each other with no air gap between them. Each measurement was taken three times and the standard deviation (SD) was calculated to ensure that the data is accurate. Only measurements with $\mathrm{SD}<1$ were considered.

Cole-Cole model was used to fit the experimental impedance data and to predict the dielectric properties over the measured frequency range (Tarasov and Titov, 2013)(Ayllon et al., 2009) (Said and Varadan, 2009). A response similar to a Cole-Cole plot indicates that the TMM can be treated as a biological tissue (skin in this case).

\subsection{Electrode Polarization Effect}

Electrode polarization is an impedance formed due to the accumulation of charges at the electrode-TMM interface. It is more prominent at lower frequencies, and therefore needs to be addressed to calculate the true impedance.

$$
Z_{m}=Z_{p}+Z_{\text {true }}
$$

where $Z_{m}, Z_{p}, Z_{\text {true }}$ are the measured impedance, impedance due to polarization and true impedance respectively.

The polarization impedance $Z_{p}$ behaves like a frequency-dependent RC circuit, with the resistor $R_{p}$ and capacitor $C_{p}$ in series (see figure 15) (Prodan and Bot, n.d.)(Schwan, 1968).

$$
C_{p}=\frac{A}{\omega^{m}}, R_{p}=\frac{B}{\omega^{n}}
$$

Where $\mathrm{A}, \mathrm{B}, \mathrm{m}, \mathrm{n}$ depends on the electrode and sample's properties and $\omega=2 \pi f_{(\mathrm{Hz})}$. 


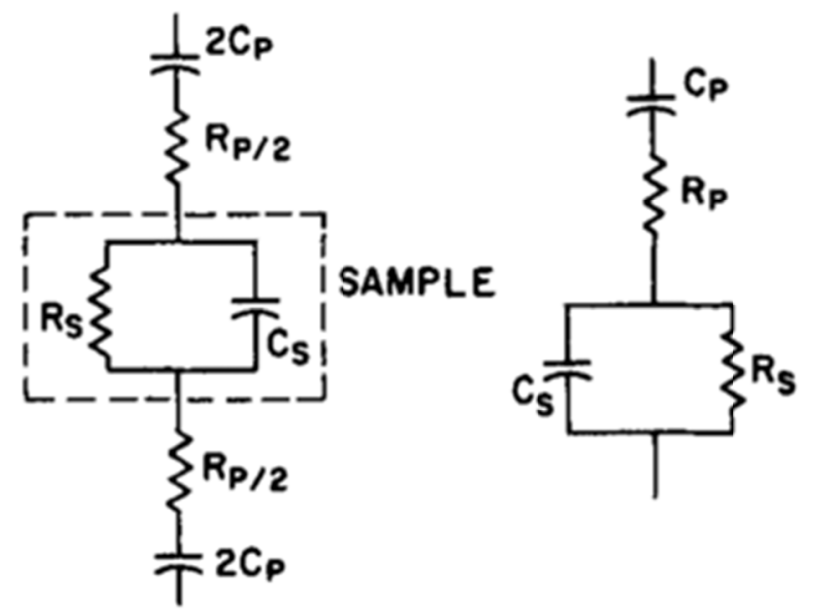

Figure 15. Equivalent circuits with polarization impedance in series with the sample

A curve-fitting model using the Error Sum of Squares (SSE) was developed in MATLAB to find the most appropriate values of the parameters in equation (7) for each TMM.

$Z_{p}$ was subtracted from the measured $Z_{m}$ to evaluate $Z_{\text {true }}$ (see equation 6).

\section{Results}

Five types of TMMs were developed in this study as mentioned in section II. This section demonstrates the results obtained by mechanical and electrical testing of each TMM.

The mechanical testing shows the stress-strain plot for TMMs with varying Young's Modulus (YM) on changing the ingredients' concentrations.

The electrical properties of the TMMs were depicted by a plot of their permittivity (dielectric constants) and conductivity with varying frequencies.

\subsection{Oil in Gelatin TMM}

Mechanical properties

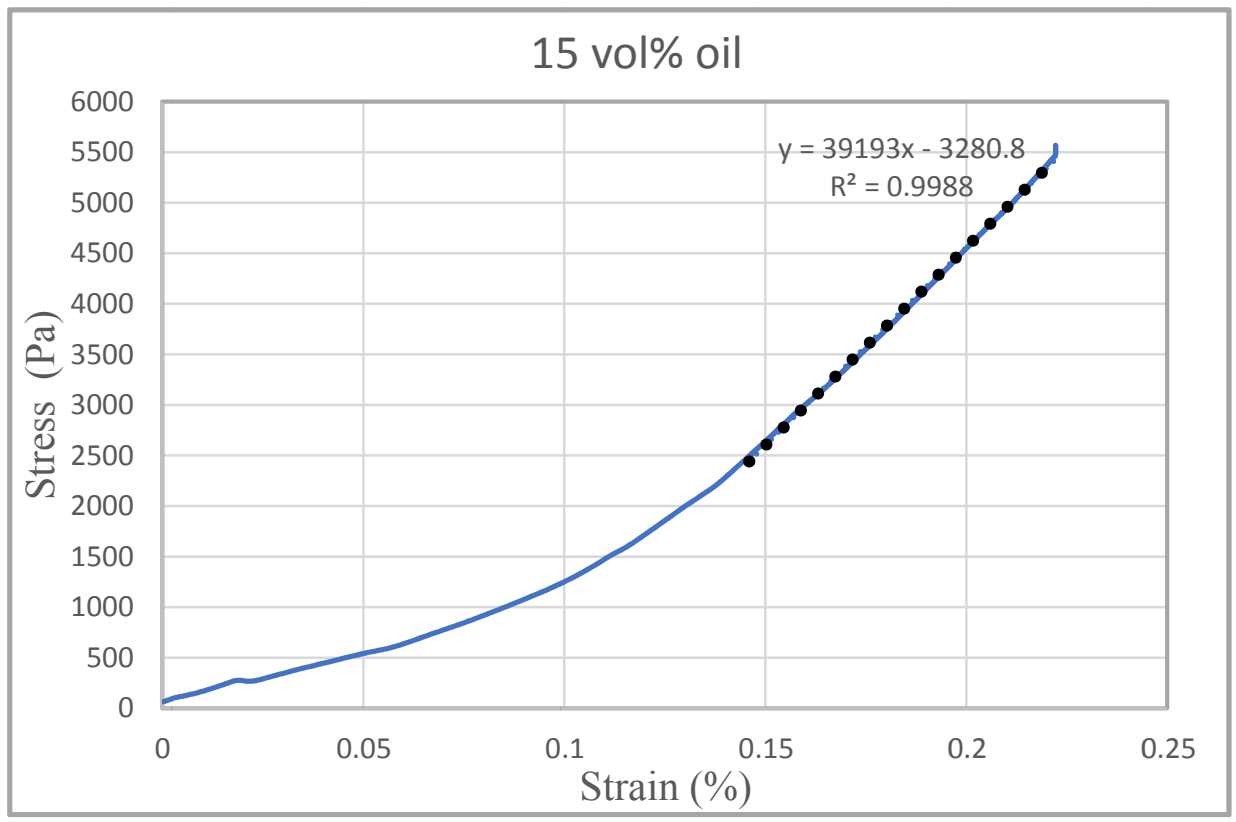

Figure 16: The stress-strain plot of $15 \%$ oil content sample with a linear trend line. 
Table 11. YM calculated from Stress-strain plots on increasing Oil in gelatin

\begin{tabular}{cccccccccc}
\hline Samples & $\mathbf{1}$ & $\mathbf{2}$ & $\mathbf{3}$ & $\mathbf{4}$ & $\mathbf{5}$ & $\mathbf{6}$ & $\mathbf{7}$ & $\mathbf{8}$ & $\mathbf{9}$ \\
\hline $\begin{array}{c}\text { Oil content (In } \\
\text { volume) }\end{array}$ & $0 \%$ & $5 \%$ & $10 \%$ & $15 \%$ & $20 \%$ & $25 \%$ & $30 \%$ & $35 \%$ & $40 \%$ \\
$\begin{array}{c}\text { Young's } \\
\text { modulus (Pa) }\end{array}$ & 50832 & 50792 & 40100 & 39193 & 38211 & 33053 & 28352 & 19610 & 8249 \\
\hline
\end{tabular}

Electrical properties

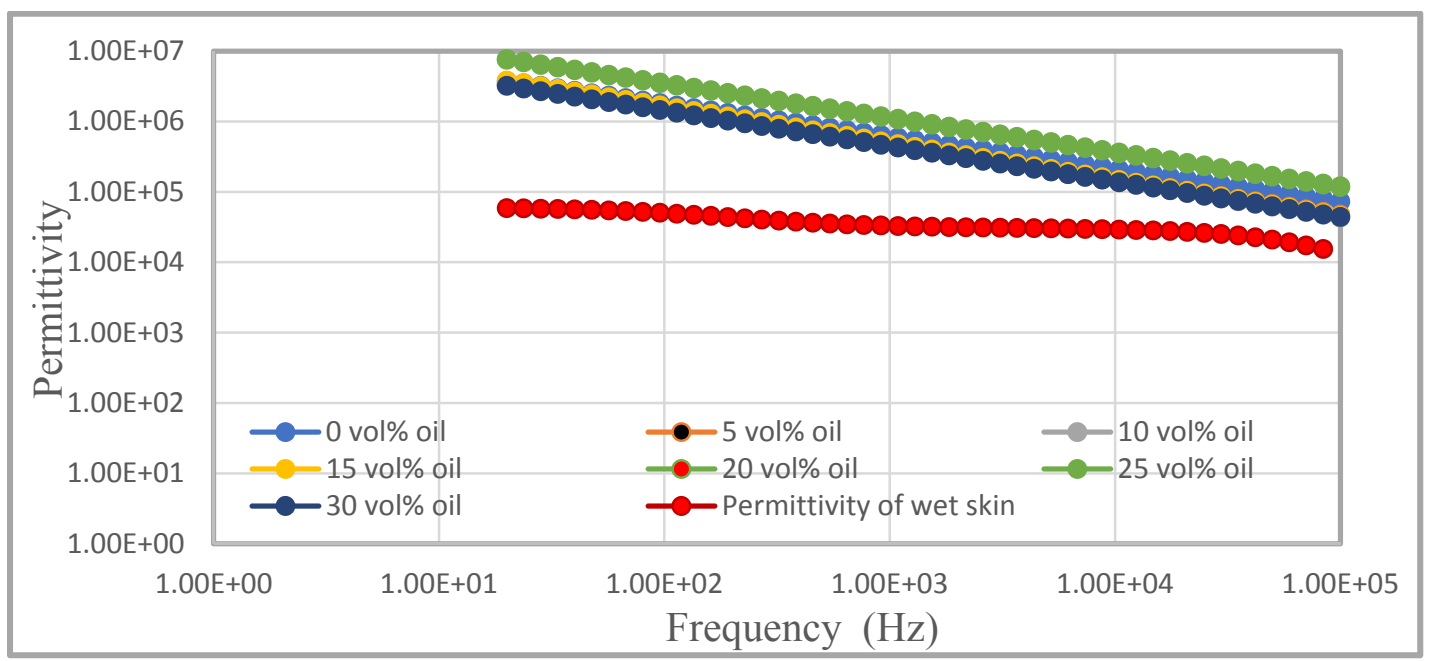

Figure 17. The permittivity of the oil-in-gelatin TMMs and actual skin

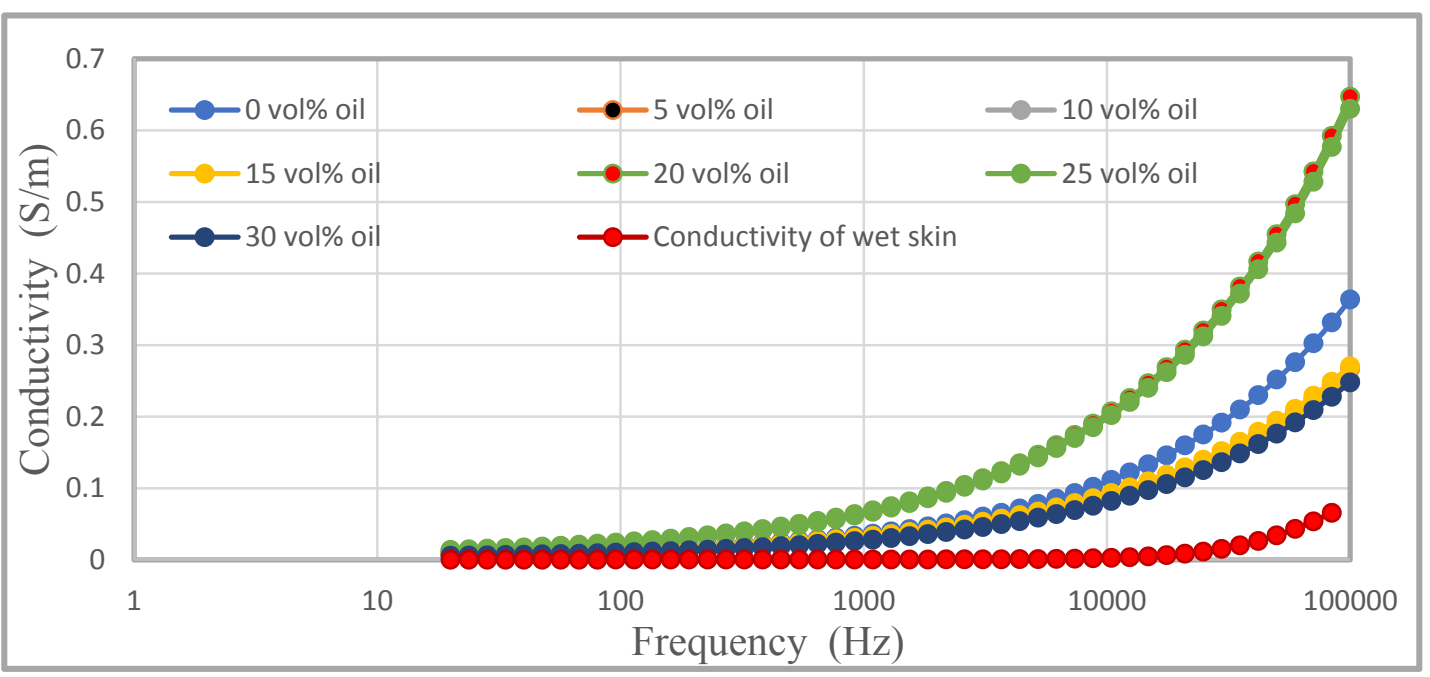

Figure18. The conductivity of the oil-in-gelatin TMMs and actual skin 


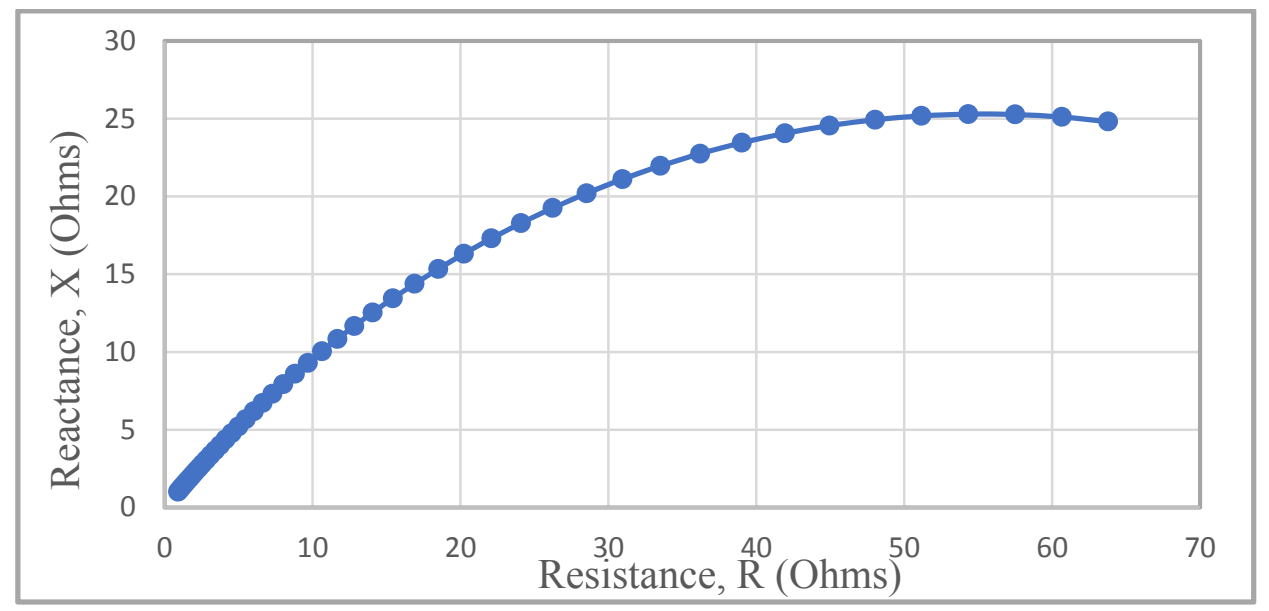

Figure 19. Cole-Cole plot for the 20 vol\% oil sample

\subsection{Lignin/Graphene Nanopowder TMM}

Mechanical Properties

Lignin

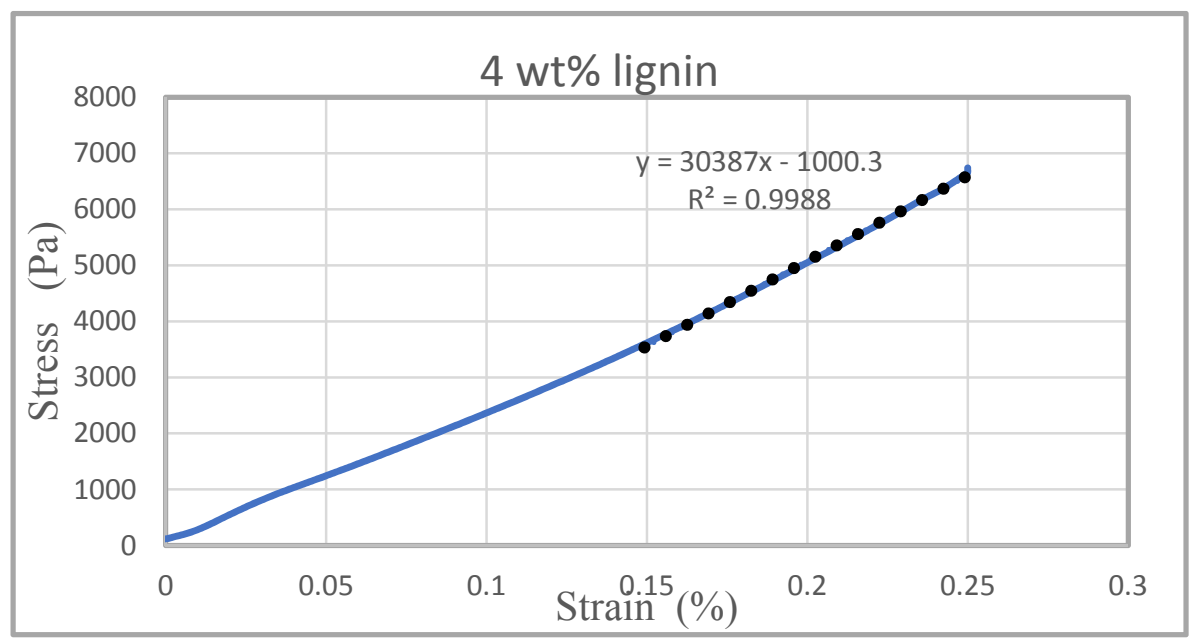

Figure 20. The stress-strain plot of oil-in-gelatin sample on adding $4 \mathrm{wt} \%$ lignin

Table 12. YM calculated from Stress-strain plots on increasing Lignin concentration in Oil +gelatin mixture

\begin{tabular}{ccccc}
\hline Samples & $\mathbf{1}$ & $\mathbf{2}$ & $\mathbf{3}$ & $\mathbf{4}$ \\
\hline $\begin{array}{c}\text { Lignin content } \\
(\mathbf{w t} \%)\end{array}$ & $0 \%$ & $2 \%$ & $4 \%$ & $6 \%$ \\
$\begin{array}{c}\text { Young's modulus } \\
(\mathbf{P a})\end{array}$ & 38211 & 28243 & 30387 & 33848 \\
\hline
\end{tabular}


Graphene Nanopowder

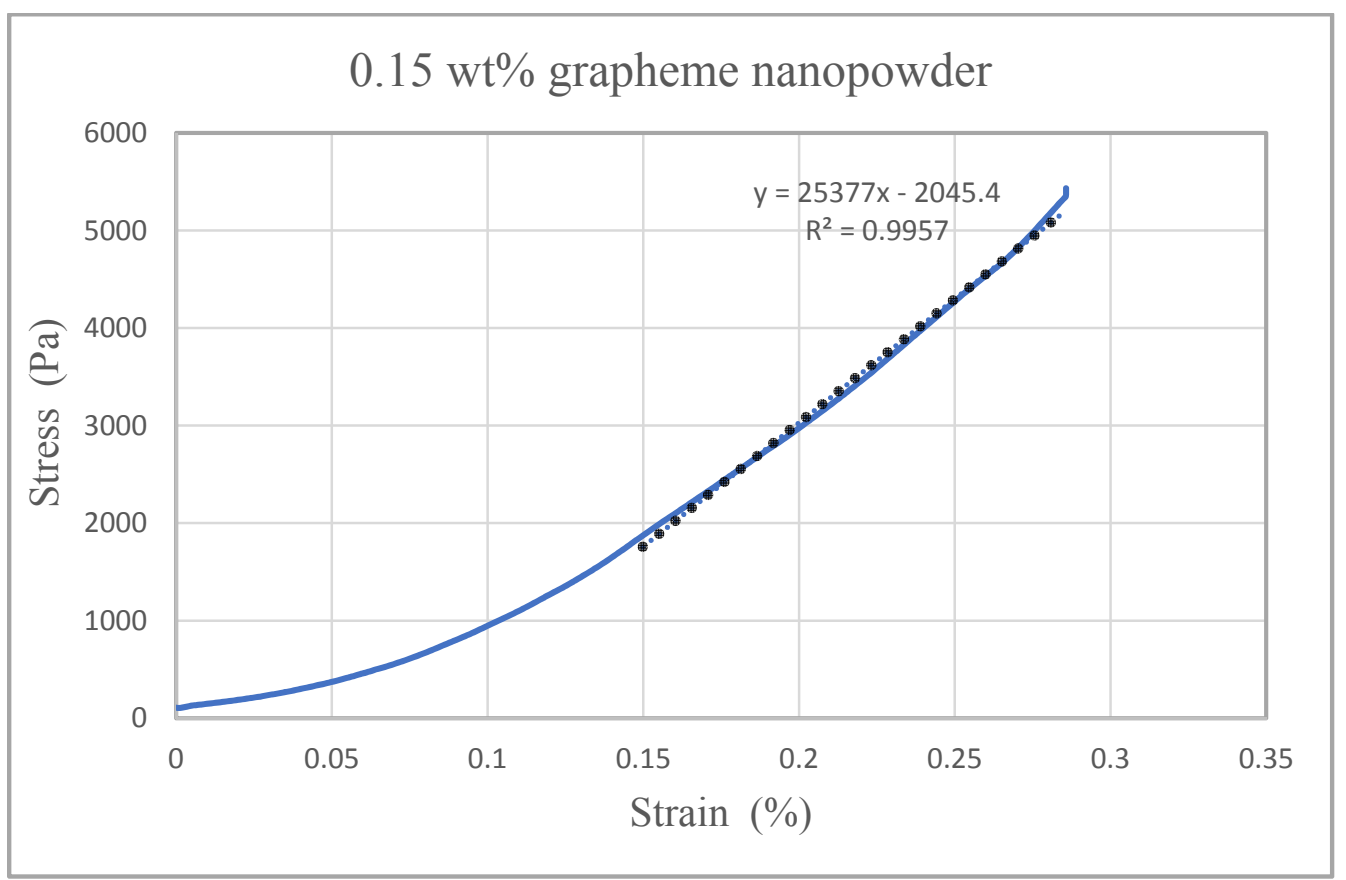

Figure 21. The stress-strain plot of oil-in-gelatin sample on adding $0.15 \mathrm{wt} \%$ graphene nanopowder

Table 13. YM calculated from Stress-strain plots on increasing Graphene Nanopowder in Oil + gelatin mixture

\begin{tabular}{ccccc}
\hline Samples & 1 & 2 & 3 & 4 \\
\hline $\begin{array}{c}\text { Graphene } \\
\text { Nanopowder } \\
\text { content }\end{array}$ & $0 \%$ & $0.05 \%$ & $0.1 \%$ & $0.15 \%$ \\
$\begin{array}{c}\text { (wt \%) } \\
\text { Young's modulus } \\
\text { (Pa) }\end{array}$ & 30387 & 28042 & & 25377 \\
\hline
\end{tabular}

Electrical Properties

Lignin

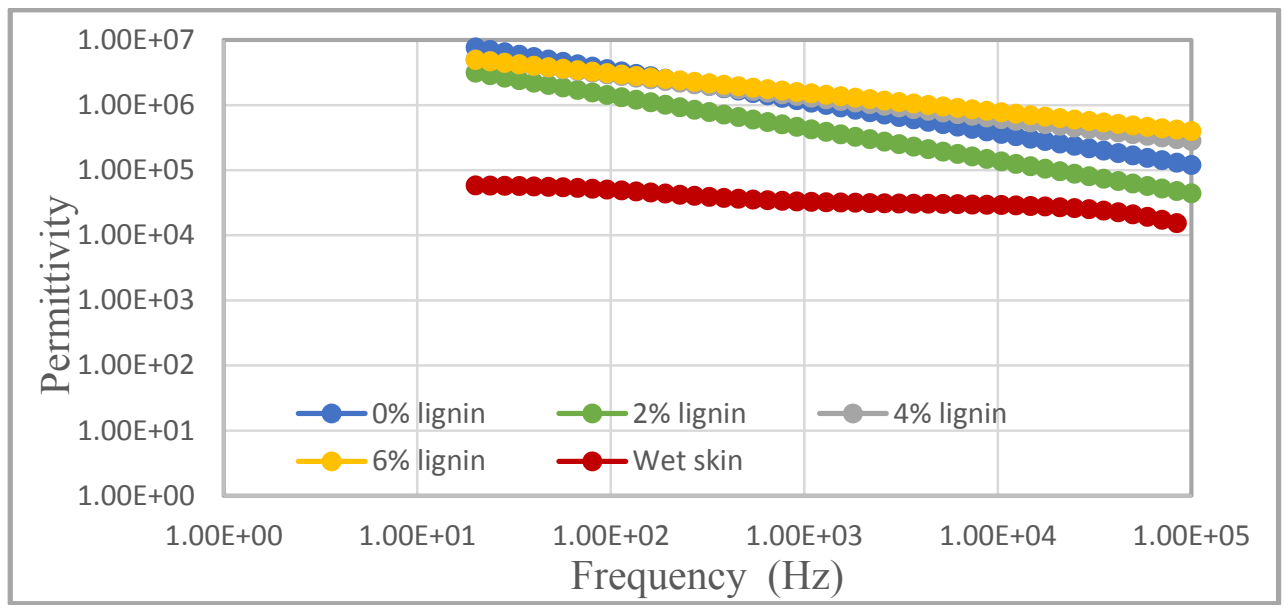

Figure 22. The permittivity of the lignin in oil+gelatin mixtures and actual skin 


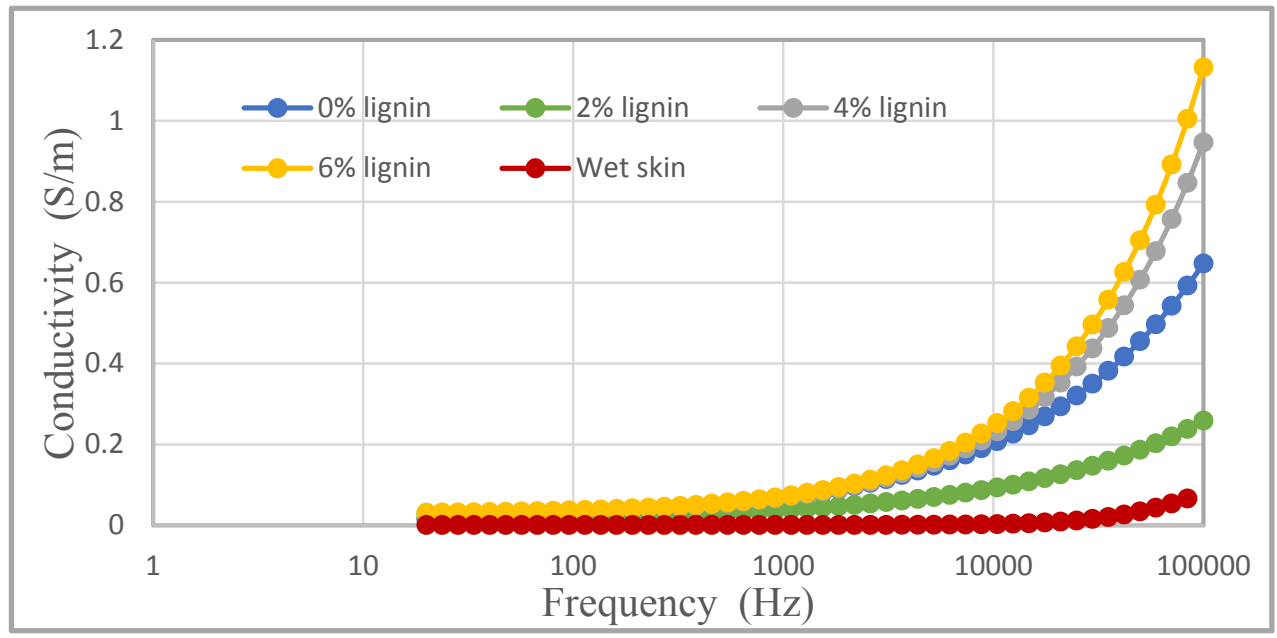

Figure 23. The conductivity of the lignin in oil+gelatin mixtures and actual skin

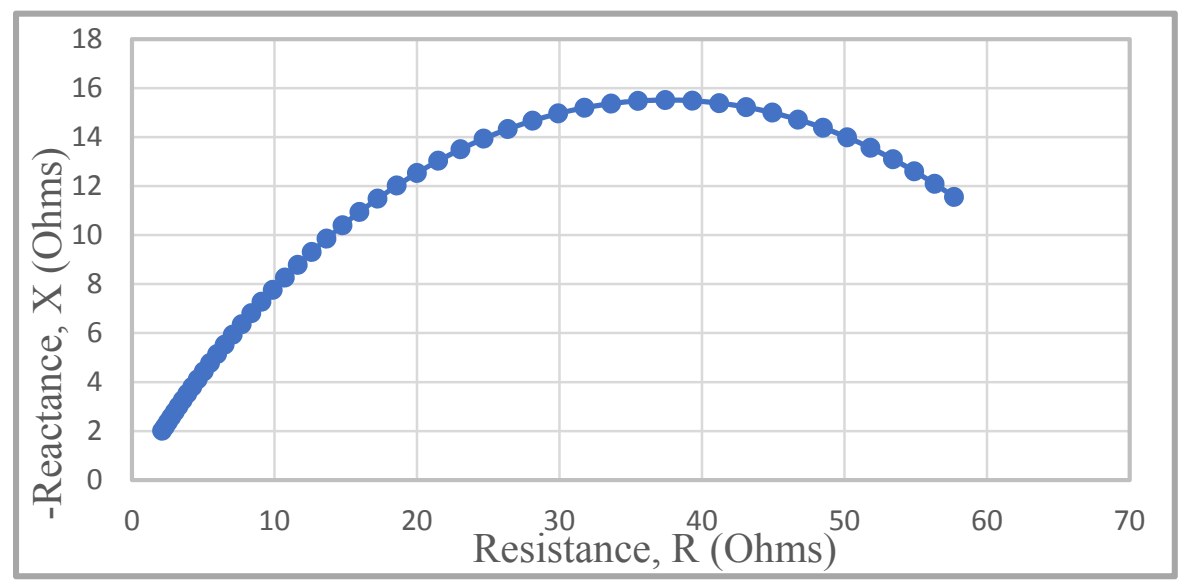

Figure 24. Cole-Cole plot on adding $2 \mathrm{wt} \%$ lignin in oil + gelatin mixture

Graphene Nano Powder

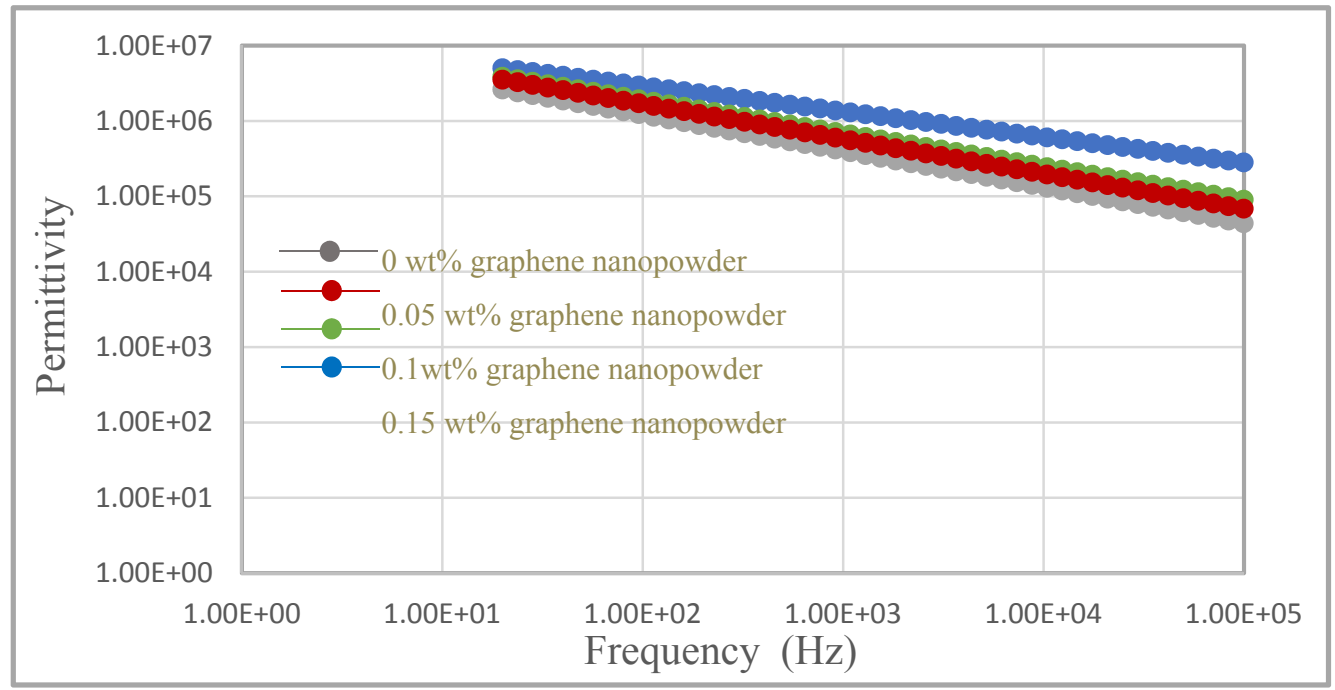

Figure 25 . The permittivity of the graphene nanopowder in oil+gelatin mixtures and actual skin 


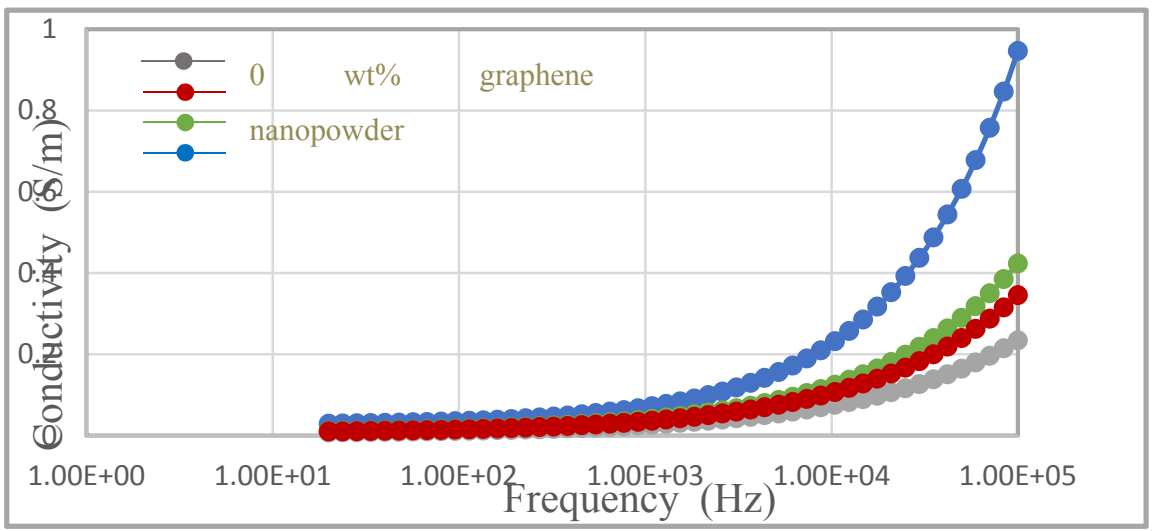

Figure 26. The conductivity of the graphene nanopowder in oil+gelatin mixtures and actual skin

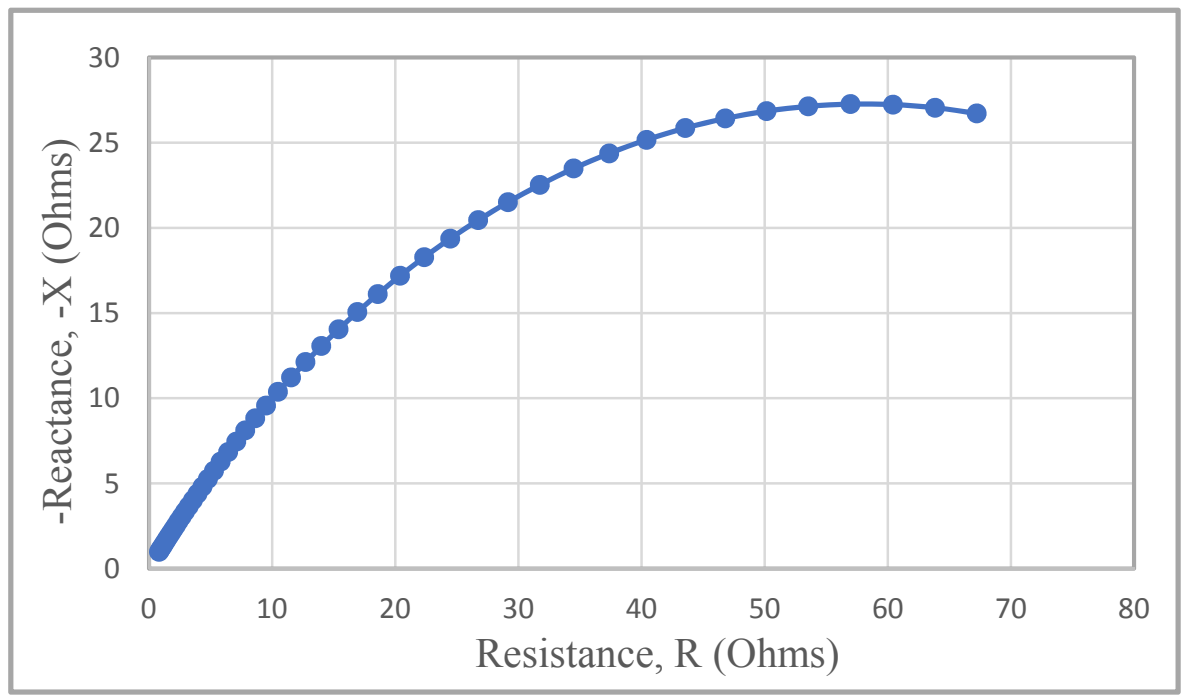

Figure 27. Cole-Cole plot on adding $0.05 \mathrm{wt} \%$ graphene nanopowder in oil + gelatin mixture

Desired mechanical properties were achieved on using gelatin, DI mixed oil, and lignin for preparing TMMs, as discussed in section IV, therefore only electrical properties of the remaining TMMs were tested. 


\subsection{Gelatin-DI TMM}

Electrical Properties

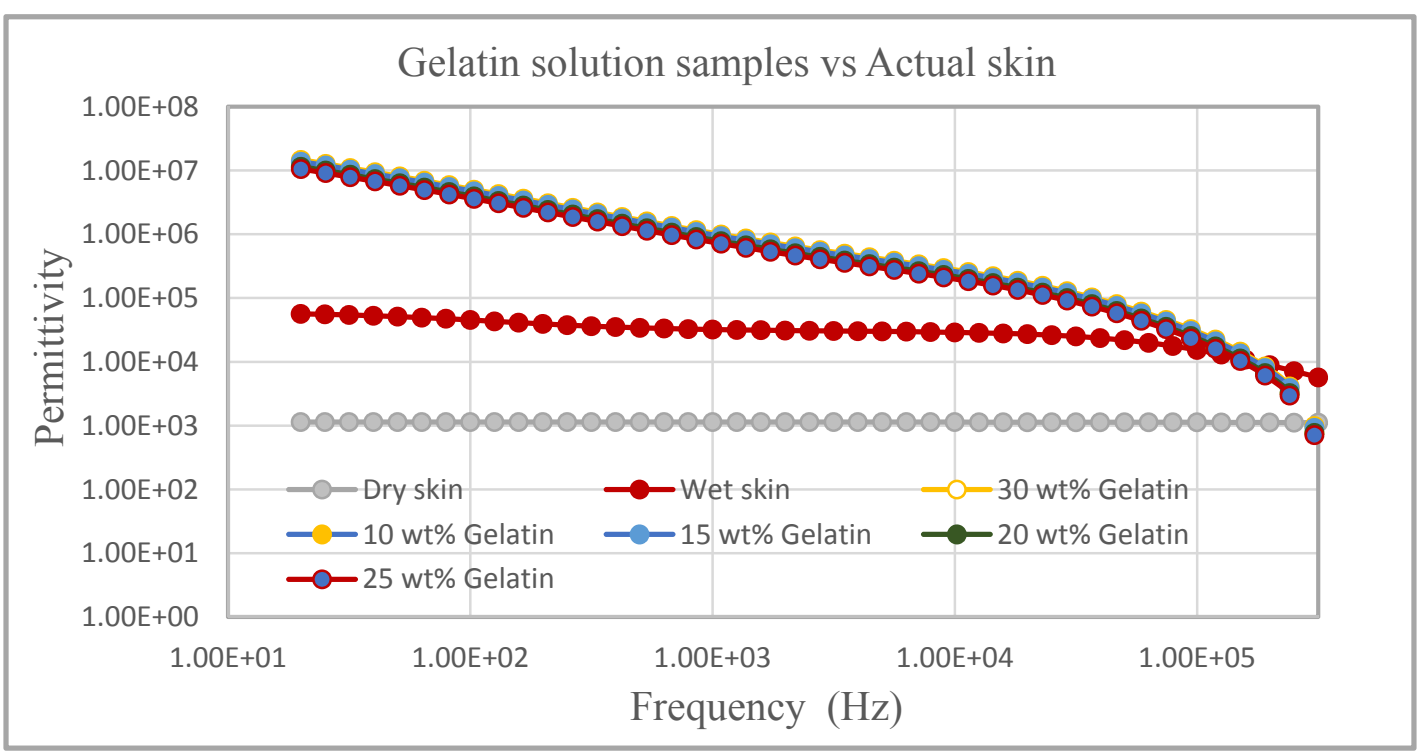

Figure 28. The permittivity of the gelatin-DI TMMs and actual skin

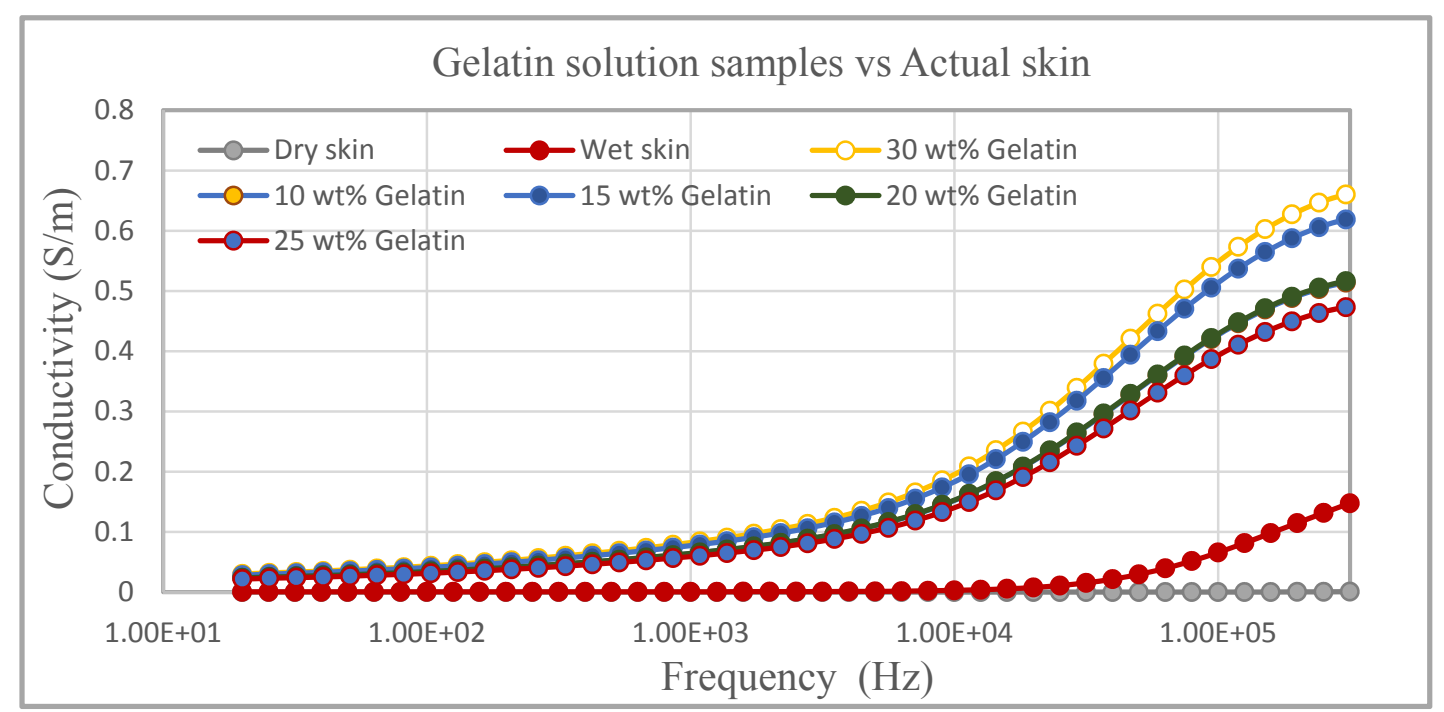

Figure 29. The conductivity of the gelatin-DI TMMs and actual skin 


\subsection{Gelatin-DI and Mixed Oil TMM}

Electrical Properties

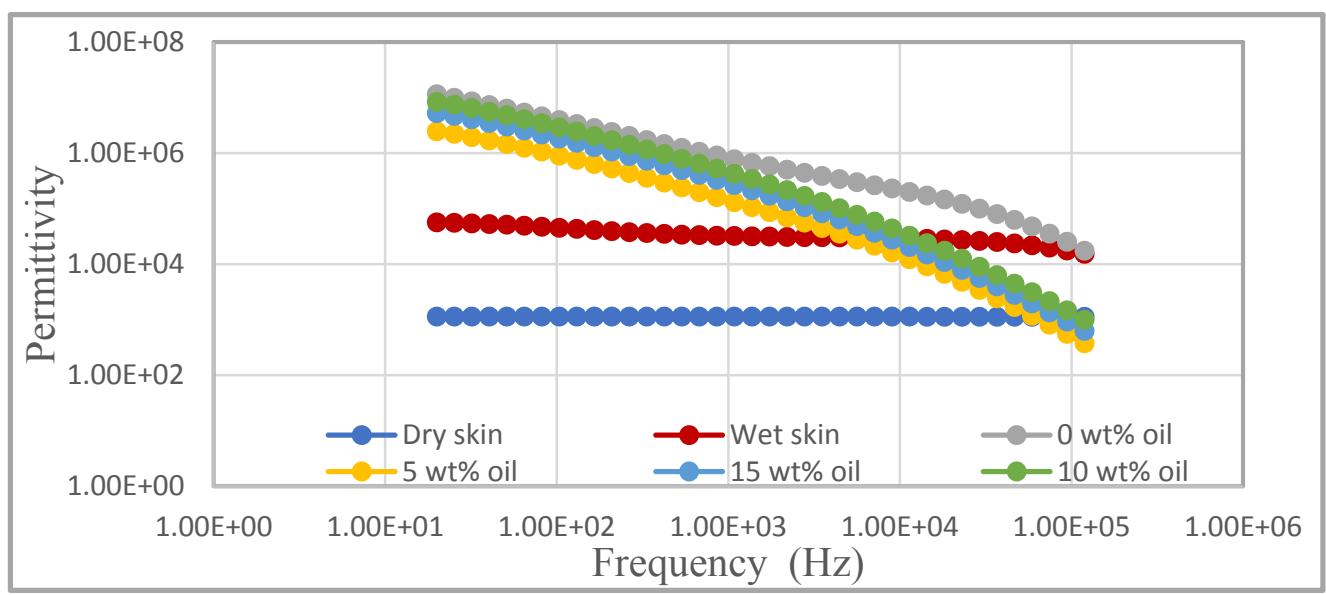

Figure 30. The permittivity of the gelatin-DI and mixed oil TMMs and actual skin

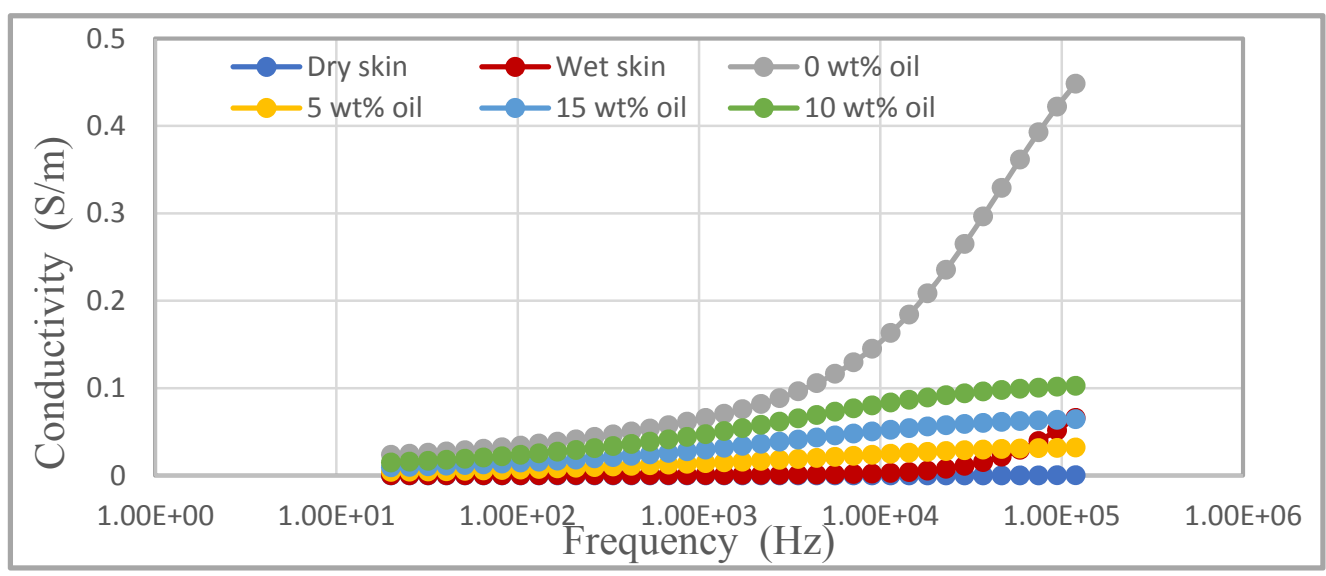

Figure 31. The conductivity of the gelatin-DI and mixed oil TMMs and actual skin

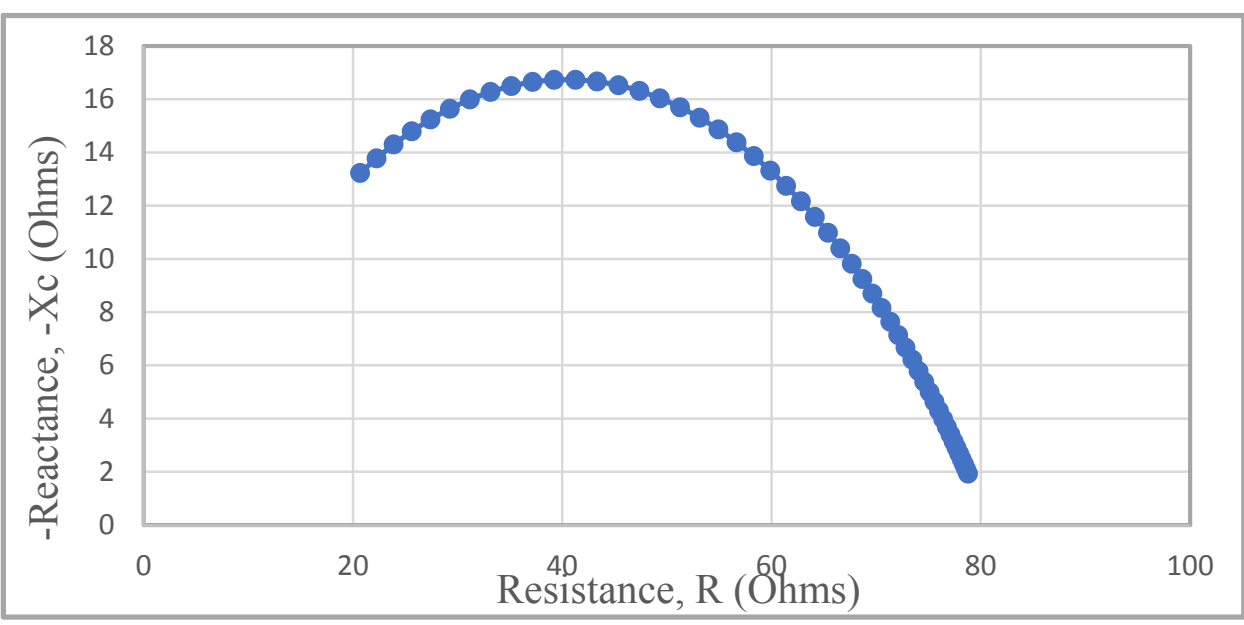

Figure 32. Cole-Cole plot on adding $5 \mathrm{wt} \%$ mixed oil in a gelatin-DI mixture 


\subsection{Gelatin-DI and lignin TMM}

Electrical Properties

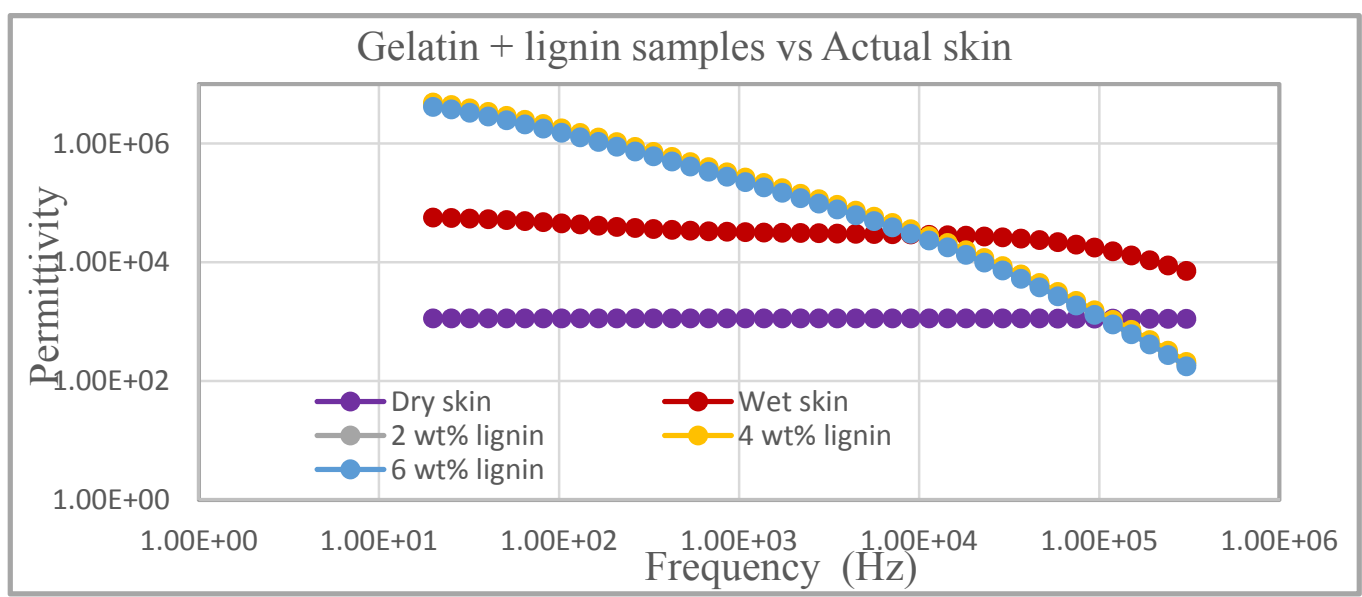

Figure 33. The permittivity of the gelatin-DI and lignin TMMs and actual skin

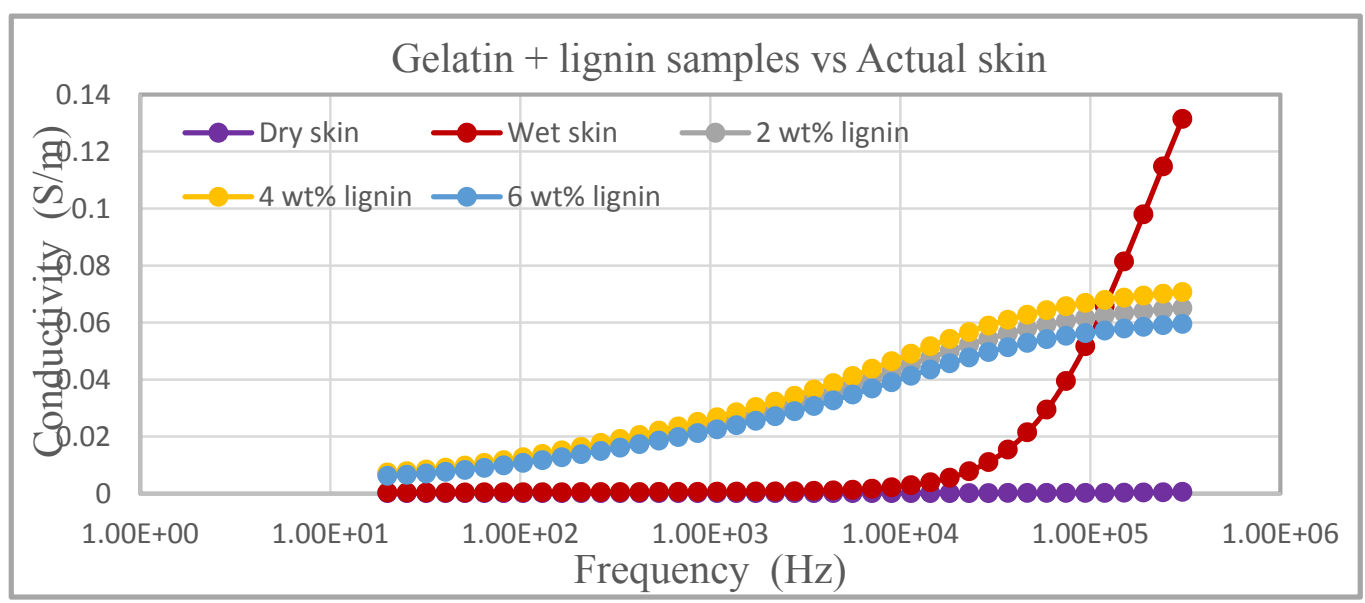

Figure 34 . The conductivity of the gelatin-DI and lignin TMMs and actual skin

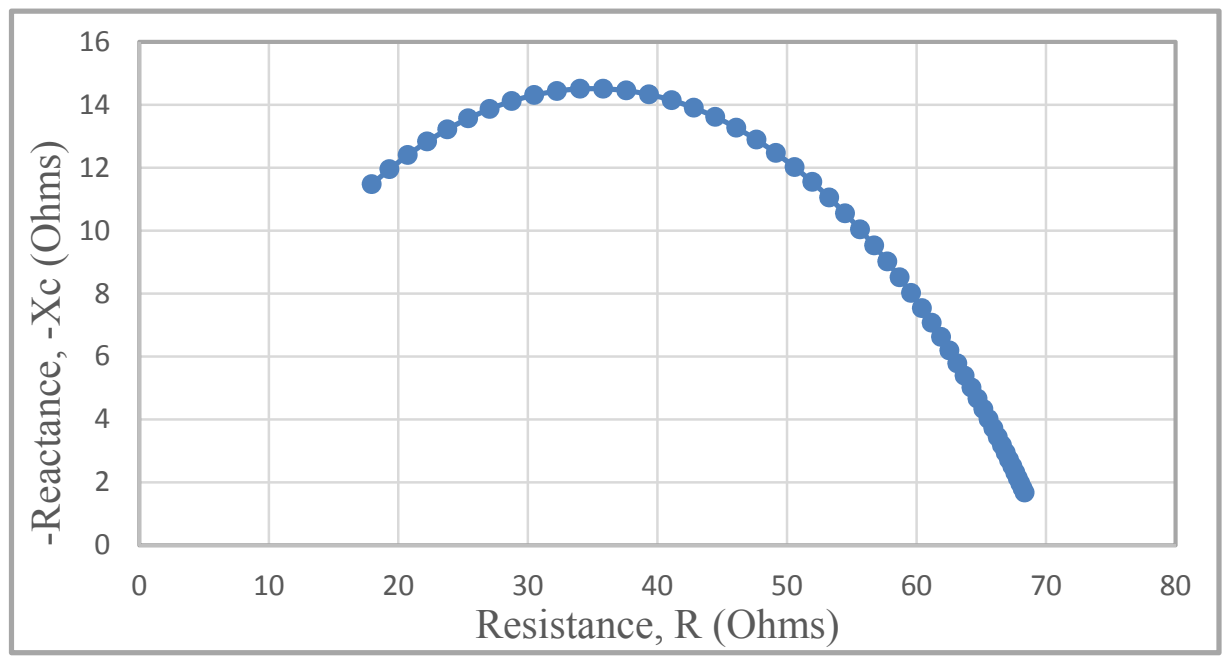

Figure 35 . Cole-Cole plot on adding $2 \mathrm{wt} \%$ lignin in a gelatin-DI mixture 


\section{Discussion}

On testing the mechanical properties of oil in gelatin TMMs, it was observed that the YM increases on increasing the concentration of oil in gelatin. The range of YM of the oil-in-gelatin phantoms varied from $8 \mathrm{kPa}$ to $50 \mathrm{kPa}$. This range is well within the YM of human skin, measured by indentation and suction techniques (5kPa to 260 $\mathrm{kPa}$ ), as stated in section I.

The samples became more fragile and stickier when large volumes of oil were added in gelatin, therefore adding more than $30 \mathrm{vol} \%$ oil in gelatin is not advisable.

The changes in permittivity and conductivity with a frequency sweep can be seen in figures 17 and 18 respectively. At lower frequencies, no significant change in the permittivity was observed on increasing the oil concentration. This outcome is different than the study performed by Lazebnik [26] in 2005 at higher frequencies $(500 \mathrm{MHz}-20 \mathrm{GHz})$. The contradiction in results can either be due to the addition of solvents- p-toluic acid (powder) and n-propanol in oil in gelatin TMMs or due to the polarization effect at low frequencies. However, the polarization effect was reduced using SSE curve fitting in Matlab, as discussed in section II, and the best Cole-Cole fit was achieved (see figure 19). The conductivities of the TMMs increased on increasing the oil concentration, which is in alignment with the trend in literature.

The addition of lignin and graphene nanopowder further reduced the YM of the TMMs (tables 12 and 13), although the YM of TMMs (25kPa-33kPa) was closer to human skin than oil-in- gelatin TMMs. Adding more than $6 \%$ lignin to the mixture wasn't feasible due to high viscosity and poor agitation of the mixture. The increase in YM on the addition of graphene nanopowder can be due to the suspension of insoluble graphene powder in the oil-gelatin based emulsions.

An increase in the permittivity and conductivities of the TMMs was observed on increasing the concentration of lignin and graphene nanopowders in oil-in-gelatin mixtures. This trend is in agreement with the findings in the literature (Lan et al., n.d.).

The measured data for both lignin and graphene nanopowders agreed with the Cole-Cole plot (figures 24 and 27), indicating their ability to mimic biological tissues.

As seen from figure 28 , the permittivity was almost unchangeable on increasing the concentration of gelatin in DI, although the conductivity of the gelatin-DI mixture was closer to wet and dry skin at $25 \mathrm{wt} \%$ concentration of gelatin in DI.

However, on adding $5 \mathrm{wt} \%$ mixed oil in gelatin-DI (see figure 30 ), the permittivity and conductivity dropped by 17067 and $0.42 \mathrm{~S} / \mathrm{m}$, respectively, which is closer to the values for dry and wet skin. Similarly, the addition of lignin reduced the permittivity and conductivity of the samples at low frequencies.

\section{Conclusion}

This study examined the mechanical and electrical performance of five kinds of TMMs at a frequency range of $20 \mathrm{~Hz}$ to $300 \mathrm{kHz}$. Amongst them, the oil-in-gelatin based TMMs were mainly standing on the contributions in (Lazebnik et al., 2005) (Lan et al., n.d.). The shreds of evidence from this study confirm that in general these tested TMMs can reach the mechanical requirement for fabricating skin phantoms.

The mechanical properties of TMMs were tested using compression tests based on the assumption that they are homogeneous in nature. More accurate research in the future should consider the heterogeneous and anisotropic properties of human skin.

This study fulfills the requirement of preparing high-quality skin phantoms using readily available materials at a lower frequency range. The electrode polarization effect, which occurs mainly at low frequencies was also removed using model fitting in Matlab, and a resemblance to the Cole-Cole plot was found in all TMMs.

All proposed skin phantom materials reflect some regularity between the dielectric properties and ingredients' concentrations. Although some exceptions cannot be explained, for example, the oil-in-gelatin based TMMs didn't show a substantial increase in permittivity at higher concentrations of oil in contrast with the findings in the literature.

The concentrations of oil, the lignin or graphene nanopowder can be further increased, but this will affect the Young's Modulus of the TMMs.

In conclusion, we propose the use of gelatin-DI TMMs doped with mixed oil or lignin for low-frequency applications. A concentration of $5-15 \mathrm{wt} \%$ of mixed oil (50 vol $\%$ kerosene and $50 \mathrm{vol} \%$ sunflower oil) or $2-6 \mathrm{wt} \%$ of lignin in Gelatin and DI mixtures are the most suitable choices for preparing TMMs for the skin. 
Future work can be done in testing the shelf life and biocompatibility of these materials.

\section{Acknowledgment}

This work was financially supported by the Institute of Biomedical Technologies, Auckland University of Technology, Auckland, New Zealand.

\section{References}

A. D. E. Lorenzo, A. Andreoli, J. Matthie \& P. Withers. (2018). Predicting body cell mass with bioimpedance by using theoretical methods: a technological review. 48, 1542-1558. https://doi.org/10.1152/jappl.1997.82.5.1542.

A. Kalra, A. Low \& A. Al Jumaily. (2016). An Overview of Factors Affecting the Skins Young. s Modulus, 4(2). https://doi.org/10.4172/2329-8847.1000156.

A. Le Bot, S. Laquie, H. Zahouani, G. Boyer \& L. Laquie. (2009). Dynamic indentation on human skin in vivo : ageing effects. 55-67. https://doi.org/10.1111/j.1600-0846.2008.00324.x.

A. Manuscript. (2011). NIH Public Access. 53(8), 1896-1902.

A. Tarasov \& K. Titov. (2013). On the use of the Cole-Cole equations in spectral induced: Polarization. Geophys. J. Int., 195(1), 352-356. https://doi.org/10.1093/gji/ggt251.

C. Gabriel, S. Gabriel \& E. Corthout. (1996). The dielectric properties of biological tissues: I. Literature survey. Phys. Med. Biol., 41(11), 2231-2249. https://doi.org/10.1088/0031-9155/41/11/001.

C. Prodan\& C. Bot. Correcting the polarization effect in low frequency Dielectric Spectroscopy, 1-16.

D. Ayllon, F. Seoane, K. Institutet \& R. Gil-pita. (2009). Cole Equation and Parameter Estimation from Electrical Bioimpedance Spectroscopy Measurements - A Comparative Study July. https://doi.org/10.1109/IEMBS.2009.5334494.

D. Popovic. (2005). Precision Open-Ended Coaxial Probes for In Vivo and Ex Vivo Dielectric Spectroscopy of Biological Tissues at Microwave Frequencies. 53(5), 1713-1722. https://doi.org/10.1109/TMTT.2005.847111.

E. L. Madsen, J. A. Zagzebski \& G. R. Frank. (1982). OIL-IN-GELATIN DISPERSIONS FOR USE AS ULTRASONICALLY TISSUE-MIMICKING MATERIALS. 8(3), 277-287.

E. Porter, J. Fakhoury, R. Oprisor, M. Coates \& M. Popovi. Improved Tissue Phantoms for Experimental Validation of Microwave Breast Cancer Detection, 4-8.

H. P. Schwan. (1968). Electrode Polarization Impedance and Measurements in Biological Materials. Ann. N. Y. Acad. Sci., 148(1), 191-209. https://doi.org/10.1111/j.1749-6632.1968.tb20349.x.

H. P. Schwan. (1994). Electrical properties of tissues and cell suspensions: mechanisms Inand models. Proc. 16th Annu. Int. Conf. IEEE Eng. Med. Biol. Soc, 70-71.

J. Garrett, S. Member, E. Fear \& S. Member. (2014). Stable and Flexible Materials to Mimic the Dielectric Properties of Human Soft Tissues. 13， 599-602. https://doi.org/10.1109/LAWP.2014.2312925.

J. Moll \& W. Dennis. Experimental Phantom for Contrast Enhanced Microwave Breast Cancer Detection Based on 3D-Printing Technology, 3-6.

J. Orschulik \& T. Menden. (2017). Optimizing the Measurement Frequency in Electrical Impedance Tomography. (1), 1-5.

J. R. Matthie. (2008). Bioimpedance measurements of human body composition: critical analysis and outlook. 239-261. https://doi.org/10.1586/17434440.5.2.239.

K. S. Cole \& R. H. Cole. (1941). Dispersion and absorption in dielectrics I. Alternating current characteristics. $J$. Chem. Phys, 9(4), 341-351. https://doi.org/10.1063/1.1750906.

K. S. Kenneth S. Cole. (1972). Membranes, ions \& impulses : a chapter of classical biophysics. University of California Press.

Kalra A, Lowe A \& Al-Jumaily A.M. (2016). Mechanical behaviour of skin: a review. Journal of Material Sciences and Engineering. https://doi.org/10.4172/2169-0022.1000254. 
L. Singh, S. Singh \& D. Singh. (2016). Optik Development and modeling of the dielectric properties of tissue-mimicking phantom materials for ultra-wideband microwave breast cancer detection. Opt. - Int. J. Light, Electron Opt, 127(4), 2217-2225 https://doi.org/10.1016/j.ijleo.2015.10.215.

L. U. C. C. Abrelli, F. E. W. G. Rillo, D. I. R. T. S. Ampaio, A. N. A. O. C. Arneiro \& T. H. E. O. Z. P. Avan. (2017). Original Contribution ACOUSTIC AND ELASTIC PROPERTIES OF GLYCEROL IN OIL-BASED GEL PHANTOMS. 43(9), 2086-2094 https://doi.org/10.1016/j.ultrasmedbio.2017.05.010.

M. Lazebnik, E. L. Madsen, G. R. Frank \& S. C. Hagness. (2005). Tissue-mimicking phantom materials for narrowband and ultrawideband microwave applications. 50, 4245-4258 https://doi.org/10.1088/0031-9155/50/18/001.

P. J. Riu \& D. Anton. (2010). Performance assessment of EIT measurement systems. J. Phys. Conf. Ser., 224(1), 0-4 https://doi.org/10.1088/1742-6596/224/1/012015.

P. M. Meaney. (2012). Clinical microwave tomographic imaging of the calcaneus: A first-in-human case study of two subjects. IEEE Trans. Biomed. Eng, 59(12), 3304-3313 https://doi.org/10.1109/TBME.2012.2209202.

Pethig R. (1984). Dielectric Properties of Biological Materials: Biophysical and Medical Applications. IEEE T Electr Insul, EI-19(5), 453-474 https://doi.org/10.1109/TEI.1984.298769.

R. B. Groves. (2012). Computer Methods in Biomechanics and Biomedical Engineering Quantifying the mechanical properties of human skin to optimize future microneedle device design. 5842.

S. Ahn, T. I. Oh, S. C. Jun, J. Lee, J. K. Seo \& E. J. Woo. (2010). Weighted frequency-difference EIT measurement of hemisphere phantom. J. Phys. Conf. Ser., 224(1), 0-4. https://doi.org/10.1088/1742-6596/224/1/012059.

S. Gabriel, R. W. Lau \& C. Gabriel. (1996). The dielectric properties of biological tissues .3. Parametric models for the dielectric spectrum of tissues. Phys. Med. Biol., 41(11), 2271-2293 https://doi.org/10.1088/0031-9155/41/11/003.

S. Lan. Preparation of a Carbon Doped Tissue-Mimicking Material with High Dielectric Properties for. 1-15.

T. Said \& V. V. Varadan. (2009). Variation of Cole-Cole model parameters with the complex permittivity of biological tissues. IEEE MTT-S Int. Microw. Symp. Dig, July, 1445-1448. https://doi.org/10.1109/MWSYM.2009.5165979.

T. Sugihara, T. Ohura, K. Homma \& H. H. Igawa. (1991). The extensibility in human skin: variation according to age and site. Br. J. Plast. Surg, 44(6), 418-422. https://doi.org/10.1016/0007-1226(91)90199-T.

U. G. Kyle. (2004). Bioelectrical impedance analysis - Part I: Review of principles and methods. Clin. Nutr, 23(5), 1226-1243. https://doi.org/10.1016/j.clnu.2004.06.004.

\section{Copyrights}

Copyright for this article is retained by the author(s), with first publication rights granted to the journal.

This is an open-access article distributed under the terms and conditions of the Creative Commons Attribution license (http://creativecommons.org/licenses/by/3.0/). 